\title{
Genetic Mechanisms Regulating the Spatio- temporal Modulation of Proliferation Rate and Mode in Neural Progenitors and Daughter Cells during Embryonic CNS Development
}

\section{Behzad Yaghmaeian Salmani}

\author{
$\prod_{\text {UNKODINGS UNIVRSTET }}$ \\ Department of Clinical and Experimental Medicine \\ Faculty of Medicine and Health Sciences \\ Linköping University, SE-58185 \\ Linköping, Sweden
}

Linköping 2018 
(C) Behzad Yaghmaeian, 2018

Front cover: Confocal image of E15.5 mouse forebrain immunostained for Sox2 (green) and Tbr2/Eomes (magenta).

Back cover: Wide-field fluorescent image of a 3-day chicken embryo, expressing electroporated pCAGGS-GFP plasmids in the brain and optic cup (green; lateral view).

Published articles I, II and III have been reprinted with permission of the copyright holders.

Printed in Sweden by LiU-Tryck, Linköping, Sweden, 2018

ISBN: 978-91-7685-277-4

ISSN: 0345-0082 
"That which can be asserted without evidence, can be dismissed without evidence."

(Christopher Hitchens) 


\section{Faculty Opponent}

Professor Mattias Mannervik

Department of Molecular Biosciences,

The Wenner-Gren Institute

Stockholm University, Sweden

\section{Supervisor}

Professor Stefan Thor

Department of Clinical and Experimental Medicine

Faculty of Health Sciences

Linköping University, Sweden

\section{Co-Supervisor}

Professor Jan-Ingvar Jönsson

Department of Clinical and Experimental Medicine

Faculty of Health Sciences

Linköping University, Sweden

\section{Members of the examination board}

Professor Fredrik Elinder

Department of Clinical and Experimental Medicine

Faculty of Health Sciences

Linköping University, Sweden

Docent, Anne Uv

Department of Medical Biochemistry and Cell biology

Institute of Biomedicine

University of Gothenburg, Sweden

Associate Professor Urban Friberg

Department of Physics, Chemistry and Biology (IFM)

Linköping University, Sweden 


\section{Abstract}

The central nervous system (CNS) is a hallmark feature of animals with a bilateral symmetry: bilateria and can be sub-divided into the brain and nerve cord. One of the prominent properties of the CNS across bilateria is the discernible expansion of its anterior part (brain) compared with the posterior one (nerve cord). This evolutionarily conserved feature could be attributed to four major developmental agencies: First, the existence of more anterior progenitors. Second, anterior progenitors are more proliferative. Third, anterior daughter cells, generated by the progenitors, are more proliferative. Forth, fewer cells are removed by programmed cell death (PCD) anteriorly. My thesis has addressed these issues, and uncovered both biological principles and genetic regulatory networks that promote these A-P differences. I have used the Drosophila and mouse embryonic CNSs as model systems. Regarding the $1^{\text {st }}$ issue, while the brain indeed contains more progenitors, my studies demonstrate that this only partly explains the anterior expansion. Indeed, with regard to the $2^{\text {nd }}$ issue, my studies, on both the Drosophila and mouse CNS, demonstrate that anterior progenitors divide more extensively. Concerning the $3^{\text {rd }}$ issue, in Drosophila we identified a gradient of daughter proliferation along the A$\mathrm{P}$ axis of the developing CNS with brain daughter cells being more proliferative. Specifically, in the brain, progenitors divide to generate a series of daughter cells that divide once (Type I), to generate two neurons or glia. In contrast, in the nerve cord, progenitors switch during later stages, from first generating dividing daughters to subsequently generating daughters that directly differentiate (Type 0 ). Hence, nerve cord progenitors undergo a programmed Type I- $>0$ proliferation switch. In the Drosophila posterior CNS, this switch occurs earlier and is more prevalent, contributing to the generation of smaller lineages in the posterior regions. Similar to Drosophila, in the mouse brain we also found that progenitor and daughter cell proliferation was elevated and extended into later developmental stages, when compared to the spinal cord. DNA-labeling experiments revealed faster cycling cells in the brain when compared to the nerve cord, in both Drosophila and mouse. In both Drosophila and mouse, we found that the suppression of progenitor and daughter proliferation in the nerve cord is controlled by the Hox homeotic gene family. Hence, the absence of Hox gene expression in the brain provides a logical explanation for the extended progenitor proliferation and lack of Type I- $>0$ switch. The repression of Hox genes in the brain is mediated by the histonemodifying Polycomb Group complex (PcG), which thereby is responsible for the anterior expansion. With respect to the $4^{\text {th }}$ issue, we found no effect of PCD on anterior expansion in Drosophila, while this cannot be asserted for the mouse embryonic neurodevelopment as there are no genetic tools to abolish PCD effectively in mammals. Taken together, the studies presented in this thesis identified global and evolutionarily-conserved genetic programs that promote anterior CNS expansion, and pave the way for understanding the evolution of size along the anterior-posterior CNS axis. 


\section{Populärvetenskaplig sammanfattning}

Det centrala nervsystemet (CNS) är oerhört komplext, med väldigt många celler och enorm mångfald av celltyper. En annan slående egenskap hos CNS är dess främre expansion, dvs att hjärnan är mycket större än ryggmärgen. Denna främre expansion är uppenbar hos de flesta, kanske samtliga djur som har ett CNS, och verkar bli alltmer uttalad under evolutionens gång. Även om denna främre expansion är ett framträdande inslag i CNS, har vi mycket begränsad förståelse av den bakomliggande mekanismen. CNS hos primater, inklusive människor, är för komplexa och tidskrävande för att användas som modeller för att ta itu med denna fråga. Biologer utnyttjar istället mindre komplexa och mer lätthanterliga djur som modeller för att studera utvecklingen av CNS, såsom fruktflugan (Drosophila) och musen. Båda dessa arter är lämpliga biologiska modellsystem för att hjälpa oss att förstå även människans biologi, eftersom många aspekter av den genetiska kontrollen av CNS utveckling är mycket lika i hela djurriket.

Mina studier, som presenteras i denna doktorsavhandling, ledde till upptäckten av nya genetiska kontrollsystem vilka reglerar hur stamceller tillväxer i olika delar av CNS. Jag har funnit att stamceller växer snabbare och under en längre period i hjärnan, jämfört med ryggmärgen, och att detta förklarar varför CNS alltid är mer expanderat framtill. Mina studier ledde också till upptäckten att celldöd inte verkar bidra till skillnaden i storlek mellan hjärna och ryggmärg. Genom att manipulera dessa genetiska kontrollsystem på ett kontrollerat sätt kunde vi bl.a. sakta ner stamcellerna och därigenom minska hjärnans tillväxt. Förståelse av dessa genetiska kontrollsystem kommer sannolikt att påverka vår inblick i sjukdomar såsom mikrocefali och hjärntumörer. De genetiska mekanismerna som identifieras i denna avhandling hjälper oss dessutom att bättre förstå utvecklingen av CNS-storlek och komplexitet i dess främre del dvs hjärnan. 


\section{Table of Contents}

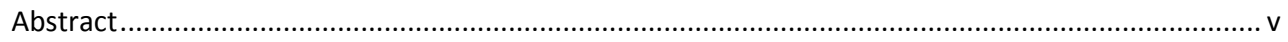

Populärvetenskaplig sammanfattning .................................................................................... vi

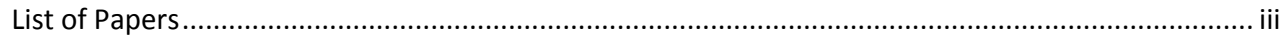

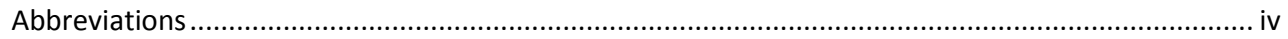

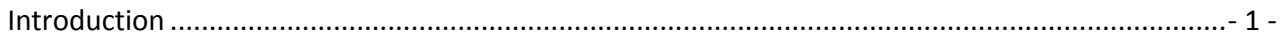

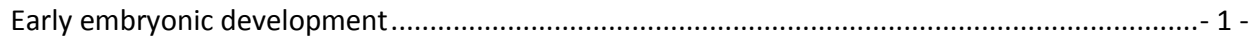

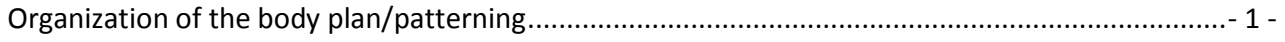

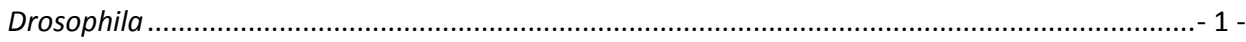

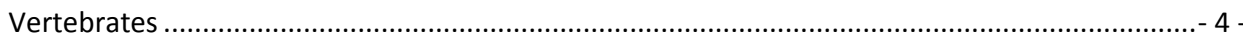

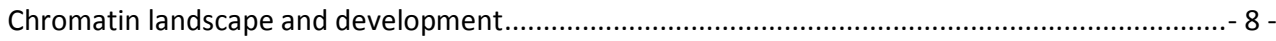

Chromatin remodeling via ATP-dependent enzymatic complexes.............................................- 10 -

Covalent Modifications of DNA and Histones............................................................................ 12 -

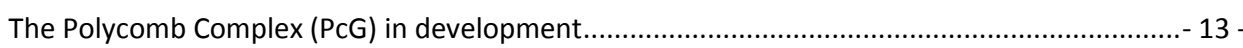

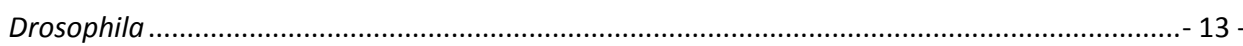

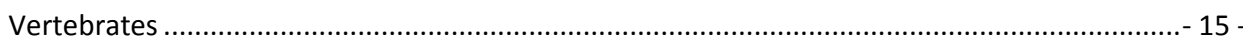

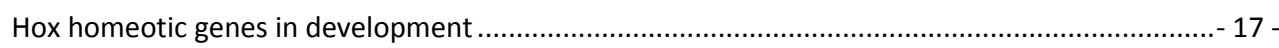

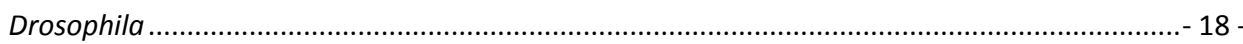

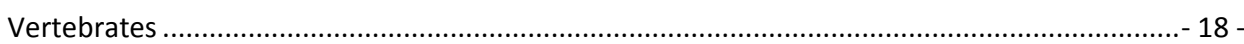

Asymmetric versus symmetric proliferation of neural progenitors ................................................ 20 -

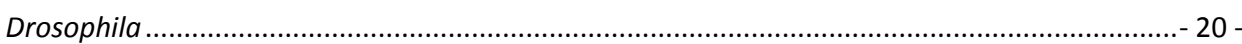

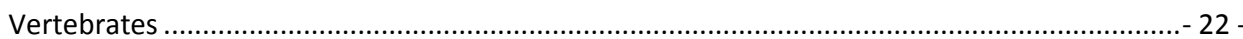

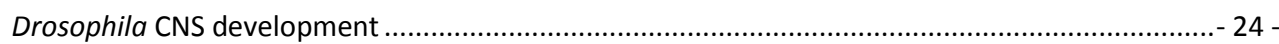

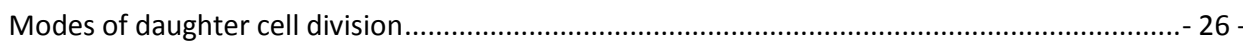

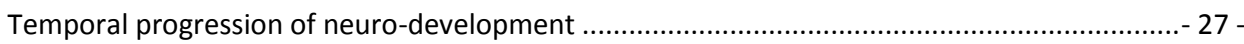

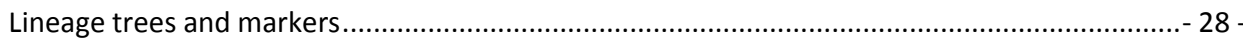

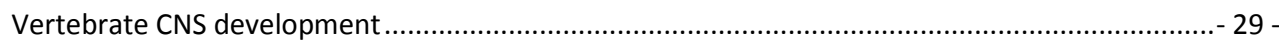

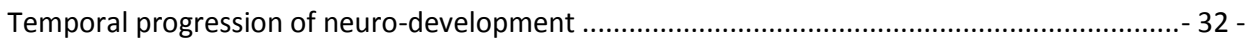

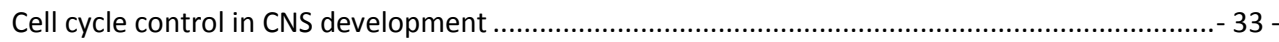

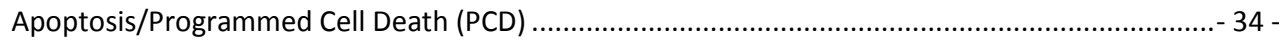

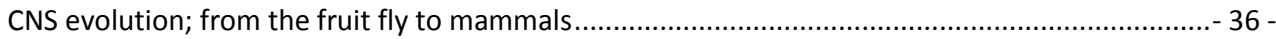

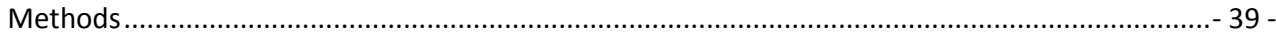

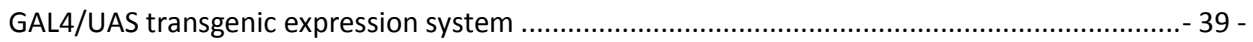




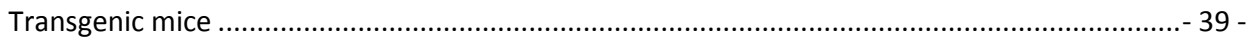

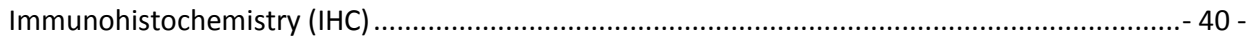

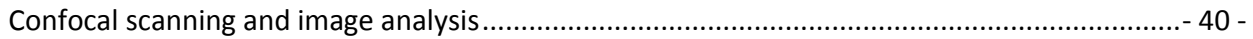

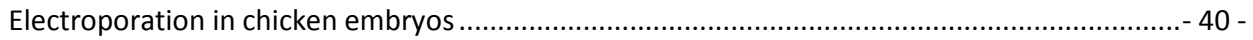

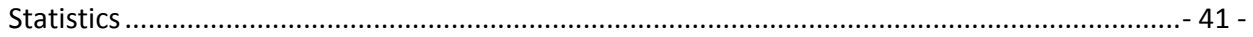

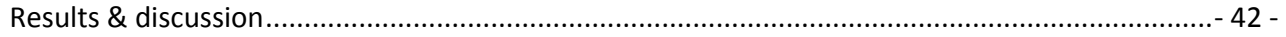

Paper I: Global Programmed Switch in Neural Daughter Cell Proliferation Mode Triggered by a

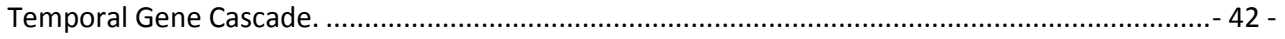

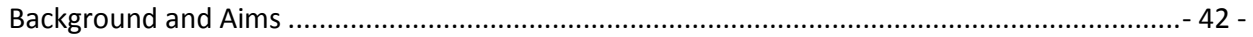

Main Findings

Paper II: Anterior-Posterior Gradient in Neural Stem and Daughter Cell Proliferation Governed by

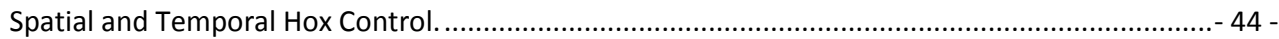

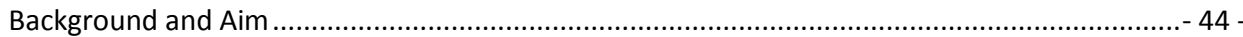

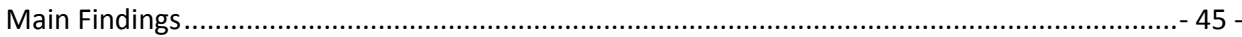

Paper III: Evolutionarily Conserved Anterior Expansion of the Central Nervous System Promoted by a

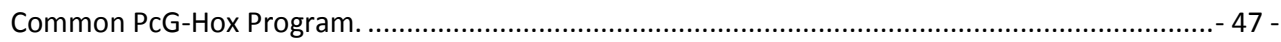

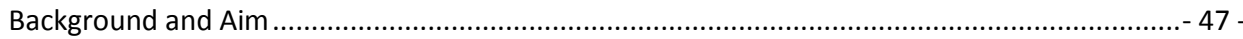

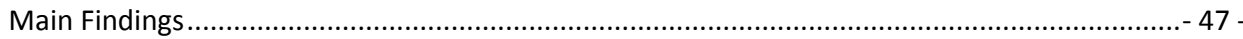

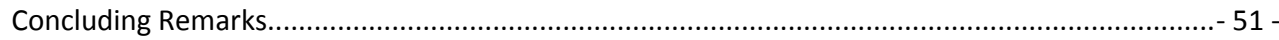

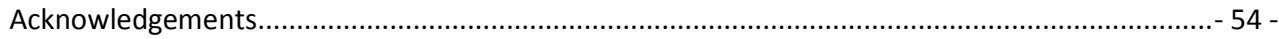

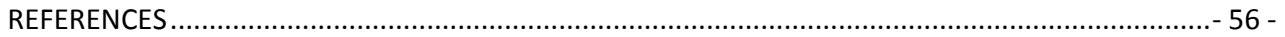




\section{List of Papers}

This thesis is based on the following papers, which will be referred to in the text by their roman numerals (I-III):

\section{Paper I}

Magnus Baumgardt*, Daniel Karlsson*, Behzad Y. Salmani, Caroline Bivik, Ryan B. MacDonald, Erika Gunnar and Stefan Thor.

Global Programmed Switch in Neural Daughter Cell Proliferation Mode Triggered by a Temporal Gene Cascade. Developmental Cell 30, 192-208, July 28, 2014 (C2014 Elsevier Inc.

*Equal contribution

\section{Paper II}

Ignacio Monedero Cobeta, Behzad Yaghmaeian Salmani and Stefan Thor.

Anterior-Posterior Gradient in Neural Stem and Daughter Cell Proliferation Governed by Spatial and Temporal Hox Control. Current Biology 27, 1161-1172, April 24, 2017 (C2017 Elsevier Ltd.

\section{Paper III}

Behzad Yaghmaeian Salmani, Ignacio Monedero Cobeta, Jonathan Rakar, Susanne Bauer, Jesús Rodriguez Curt, Annika Starkenberg and Stefan Thor.

Evolutionarily Conserved Anterior Expansion of the Central Nervous System Promoted by a Common PcG-Hox Program. Development145, April 5, 2018 @2018 the Company of Biologists Ltd. 


\section{Abbreviations}

A-P

Ap

bHLH

BMP

bNP

$\mathrm{CC}$

CNS

D-V

GFP

GMC

HD

Macroglia

MZT

NB

NEC

NP

RA

PCD

RFP

SC

$\mathrm{TF}$

UAS

VNC

ZGA
Anteroposterior

Apterous

Basic helix-loop-helix

bone morphogenic protein

basal neural progenitor

cell cycle

central nervous system

Dorsoventral

green fluorescent protein

ganglion mother cell

Homeodomain

astrocyte/oligodendrocyte

maternal-zygotic transition

Neuroblast

neuroepithelial cell

neural progenitor

retinoic acid

programed cell death

red fluorescent protein

spinal cord

Transcription factor

upstream activating sequences

Ventral nerve cord

zygotic gene activation 


\section{Introduction}

\section{Early embryonic development}

The two most defining features of multicellular organisms are reproduction and development [1]. Development, in its ontogenetic sense, consists of self-construction and self-organization which, in the matter of sexual reproduction, begins with a seemingly simple cell called zygote i.e., the fertilized egg, and continues to give rise to a full-grown organism. The building blocks for self-construction are provided via mitosis i.e., cells dividing with diminishing competence and increasing specification over developmental time. This progresses from totipotency to pluripotency, onward to multipotency, which is around late gastrulation i.e., during the formation of the three germ layers, and finally to fully-differentiated, committed cells. Selforganization is achieved via cell migration, tissue orientation and body axes formation. In bilateria (animals with a bilateral symmetry), the body axes include anterior-posterior (A-P), dorsal-ventral (D-V) and medial-lateral (right-left). Development, for each and every cell, is a journey through developmental time with changes in its competence, culminating as the cell becomes committed to a given fate via differentiation. After every cell cycle, or even in postmitotic cells over time, there are switch points of cellular fate trajectories coupled to changes in developmental competence and plasticity of cells (Waddington's concept of the epigenetic landscape [2]).

\section{Organization of the body plan/patterning}

Morphogens are signaling proteins that act in a dosage-dependent manner over a distance to induce specific cell fates [3]. Embryonic body patterning and the establishment of A-P and D$\mathrm{V}$ axes span blastula, gastrula and somitogenesis stages of embryonic development. Since A-P and $\mathrm{D}-\mathrm{V}$ axes are not established all at once, the precise spatio-temporal regulation of morphogens' signaling and distributions are also critical for proper 3D patterning of embryonic body [4].

\section{Drosophila}

The nucleus of the fertilized egg divides several times rapidly in a shared cytoplasm without cytokinesis/cleavage, which creates a syncytium. Nuclei move to the surface of the zygote to 
from the syncytial blastoderm. This takes about two hours and involves 13 rounds of division. After about three hours, cell membranes are formed around the nuclei to give rise to the cellular blastoderm. The pole cells at the posterior end of the egg will constitute the germline while cellular blastoderm will give rise to the somatic cells of the embryo. A specific group of midventral cells of the blastoderm invaginate to initiate gastrulation. The cells remaining at the egg surface will become the ectoderm, while the invaginating cells form the mesoderm and the endoderm [5]. The early processes of development are controlled by maternally-deposited factors (proteins and mRNAs) such as Bicoid (Bcd), Caudal (Cad) and Nanos (Nos), which form gradients along the A-P axis to drive segmentation of the early embryo. The anteriorlylocalized Bcd is a homeodomain (HD) transcription factor (TF), which controls the formation of anterior segments e.g., head and thorax, while Nanos, an RNA-binding protein, controls the formation of the abdominal segments [6]. These maternal factors control a hierarchy of downstream factors including gap genes, pair-rule genes, segment polarity genes and homeotic genes which further sub-divide the embryo into segments along the A-P axis [7] (Fig. 1).

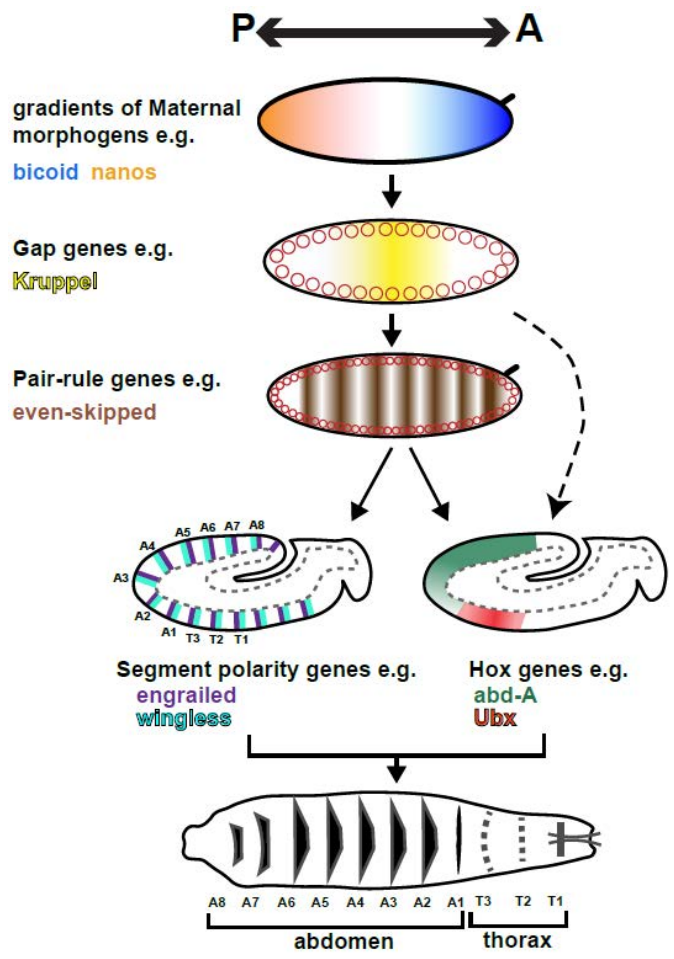

Figure 1: A-P Body patterning in Drosophila embryo. Hierarchical gene activation from maternally-deposited morphogens to segments polarity and Hox genes sequentially divide and identify body segments during embryogenesis. (adapted from Sanson, 2001). 
D-V patterning of the Drosophila embryo involves gradients of nuclear localization of Dorsal (D1) protein (vertebrate NF- $\mathrm{BB}$ ), which is mediated by gurken (grk), pipe (pip) and spatzle $(s p z)$. The local translation of grk mRNA and the localized secretion of Grk and its binding to the receptor Torpedo (EGFR) of the adjacent follicle cells define the dorsal side of the oocyte. Therefore the opposite side of the egg will be the ventral side. Pipe is secreted by the ventral follicle cells into the ventral perivitelline space which, in turn, activates Spz enzymatically. Activated Spz, present only ventrally, binds to the Toll receptor, resulting in the separation of Cactus from Dl and the nuclear localization of Dl in the ventral embryo (Fig. 2). Nuclearized Dl functions as the transcriptional activator of twist (twi) and snail (sna), which are mesodermal determinants, as well as rhomboid (rho), which is involved in neuroectoderm specification. Dl also functions as a transcriptional repressor of genes necessary for dorsal ectoderm development such as, zerknult (zen) and decapentaplegic (dpp) [8].

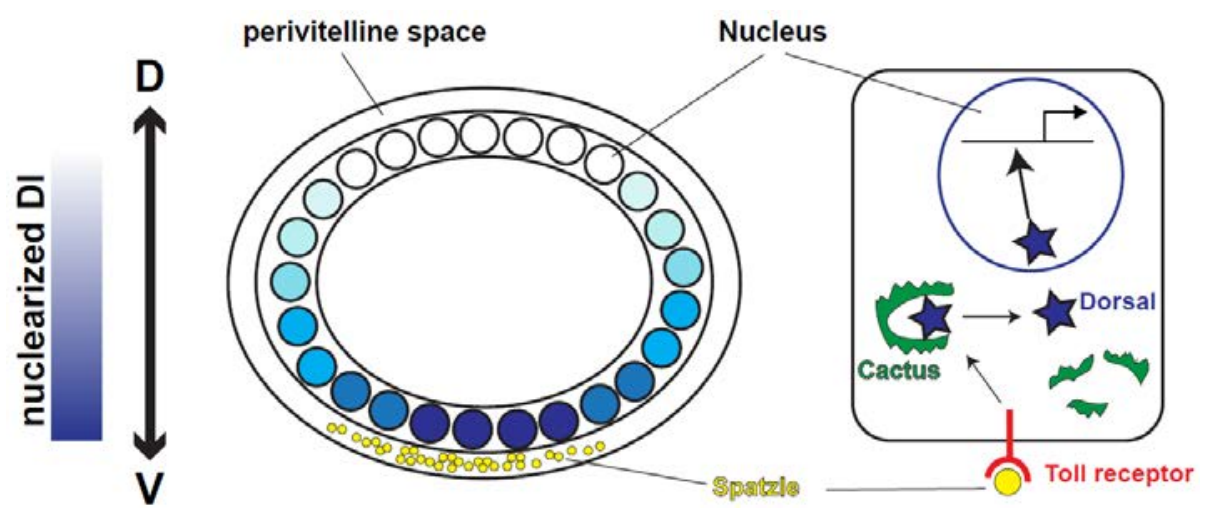

Figure 2: Gradient of nuclearized Dorsal transcription factor as a result of ventral activation of ligand; Spatzle. D1 is relieved from its cytoplasmic inhibitor Cactus via binding of Spz to the Toll receptor. Relieved Dl is then nuclearized and functions as a transcription factor (adapted from Wolpert \& Martinez Arias, Principles of Development. 5 ed. 2015).

The antagonistic effects of D1 and Dpp define the expression domains of another group of HD TFs denoted columnar genes that subdivide the neuroectoderm into three columns along the medial-lateral axis. These genes include ventral neuroblast defective ( $v n d)$, intermediate neuroblast defective (ind) and muscle specific homeobox ( $m s h$ ) [9], which are expressed in that order along the D-V axis. The short gastrulation (sog) gene is also an antagonist of Dpp. 
It is expressed in the lateral neuroepithelium and function non-autonomously to block Dpp signaling pathway dorsally [10] [11] (Fig. 3).
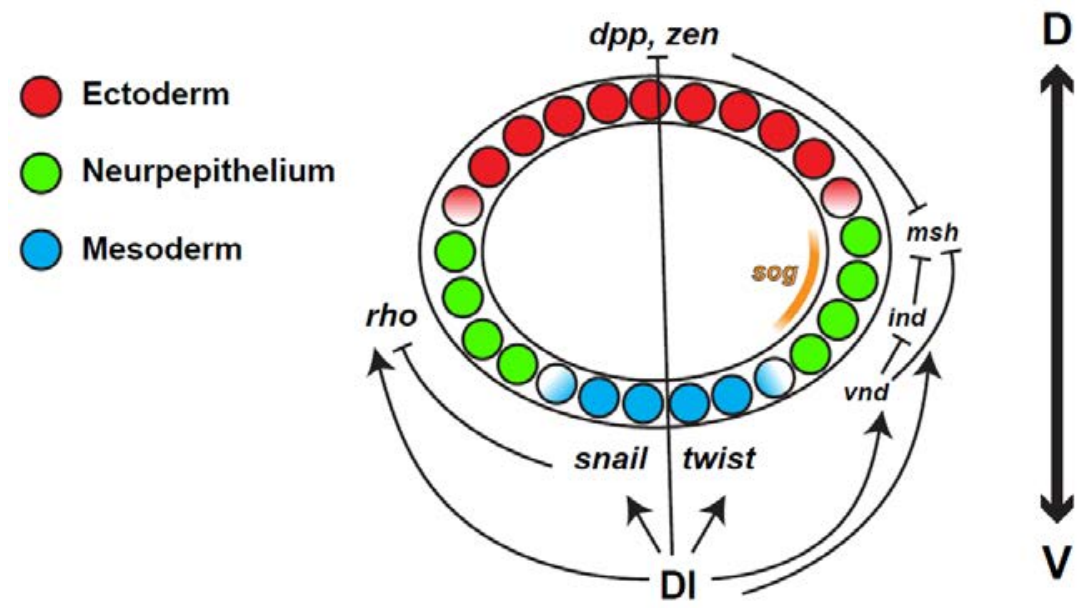

Figure 3: The gradient of the maternal TF Dorsal and its antagonistic interaction with Dpp define the expression patterns of other genes that confer axial D-V identities such as mesodermal determinants (twist and snail), rho, sog and columnar genes in neuroepithelium and the ectodermal determinants zen and $d p p$ itself. These interactions define mesoderm, neurogenic ectoderm (neuroepithelium) and epidermis (ectoderm) (adapted from Perrimon et al., 2012).

\section{Vertebrates}

Similar mechanisms of controlling body patterning seem to be at work in more derived organisms. Wnt, FGF, Nodal and Retinoic acid specify posterior regions while the graded repression of these morphogens define anterior regions. For example, zygotic Wnt, a cysteine-rich glycoprotein, activates genes needed for posterior identification via binding to the receptor Frizzled (Fz), with the assistance of co-receptors such as low-density lipoproteinrelated receptors (LRPs) and heparin-sulfate proteoglycans (HSPGs). Wnt-Fz recruits Disheveled (Dvl) and Axin 1 to the $\beta$-catenin destruction complex. The disrupted destruction complex then cannot phosphorylate $\beta$-catenin for degradation, so $\beta$-catenin accumulates, enters the nucleus and binds TCF or LEF and triggers expression of target genes $[12,13]$. At early blastula, maternal Wnt is involved in the establishment of the dorsal organizer (the Spemann organizer in amphibians; generally called the gastrula organizer) which coordinates 
cellular movements during gastrulation, formation of notochord, formation of the A-P and D$\mathrm{V}$ body axes, via graded levels of different bone morphogenetic proteins (BMPs). Wnt antagonists such as secreted Frizzled-related proteins (sFRPs) and Dickkopf (Dkk) are localized anteriorly. sFRPs can bind Wnt to prevent its binding to the receptor Fz and Dkk, which are localized in the membrane, bind the LRP co-receptors [4, 14] (Fig. 5).

Fibroblast Growth Factor (FGF) binds and activates its receptors (FGFRs) which are receptor tyrosine kinases (RTKs). Upon FGF binding, RTKs dimerize and trans-phosphorylate. The activated FGFRs then activate MAPK (mitogen-activated protein kinase) via Grb2, Ras (small GTPase) and Raf (a MAP3K) sequentially ([4, 15-17]). The FGF antagonist Sprouty (Spry), which is believed to disrupt MAPK activation via interfering with Ras-mediated activation of Raflor by the direct inhibition of Raf1, inhibits FGF signaling [18]. Since all Spry proteins from Drosophila to mouse have a C-terminal, highly conserved Rafl-binding domain (RBD), the interference at the Raf level is highly plausible as a general mode of antagonism. Wnt signaling is also believed to activate Spry expression, indicating a finetuning mechanism between Wnt and FGF expression domains. Spry is either membranebound or in the cytoplasm, and its tissue-specific localization may also control its spatiotemporal repression of FGF (Fig. 5).

Nodal is another important morphogen in early body patterning. Nodal is a secreted ligand (a member of TGF $\beta$ superfamily) which binds type I (activin-like kinase4; ALK4) and type II (activin-receptor II; ActR II) Ser/Thr kinase receptors, together with EGF-CFC co-receptor. Activated receptors then phosphorylate transcription factors Smad2 and Smad3 which are thereby nuclearized and bind their target genes [4, 19]. Nodal activity is antagonized by soluble extracellular proteins such as Lefty and Cerberus, which can bind both Nodal and EGF-CFC co-receptor, or only Nodal respectively [19]. Similar to FGF, Nodal expression in the dorsal organizer is triggered by the maternal Wnt at early blastula. However, during gastrulation, Nodal is important for mesendoderm patterning and delineation in Xenopus and zebrafish embryos i.e., higher levels of Nodal confers endodermal identity while lower levels confer mesodermal identity. Along the anteroposterior axis, Nodal promotes posterior cell fates such as trunk and tail and also induces Wnt and FGF expression which in turn confer posterior specificity (Fig. 5). So Nodal acts as a morphogen i.e., concentration-dependent, in mesendoderm patterning but also acts in A-P patterning simultaneously. Whether these two distinct roles are independent or cooperative is yet not clear [4]. 
Retinoic Acid (RA) is another important player in early body patterning, particularly in the CNS. RA is the product of sequential oxidation of retinol (vitamin A) or $\beta$-carotene into retinaldehyde and then into RA [20]. In a paracrine mode, RA modulates the expression of a wide range of target genes such as Hox genes, TGF $\beta 1$, FGF8, Pax6, Olig2, Drd2, Cdx1, Pdx1, Epo and many more $[17,21]$. Once taken up by the responding cell, the RA, which in some cells is bound by a cellular RA binding protein (CRABP) to improve its uptake, binds its nuclear receptors (RARs) which in turn dimerize with retinoid X receptors (RXRs) to form a complex which can bind RA response elements (RAREs) in DNA to regulate target gene expression. The RA-RAR-RXR complex recruits co-activator proteins with histone acetyltransferase activity (HAT). When RA is absent, RAR-RXR heterodimer recruits a corepressor complex with histone deacetylase activity (HDAC) (Fig. 4). RA also plays an important role in establishing the left-right (L-R) bilateral symmetry of somites. RA antagonists are cytochrome P450 enzymes (e.g., Cyp26 a1/b1/c1) which degrade RA. Therefore, the levels of cytochromeP450 enzymes create a gradient for RA-mediated gene regulation [22]. This is all the more interesting in light of the fact that the RA and FGF pathways interact to cross-regulate each other during the patterning of neural tube. RA represses FGF8 and interferes with MAPK signaling downstream of FGF while conversely, FGF induces Cyp26 expression in developing somites and inhibits Raldh2 and RAR in developing limb buds [17, 22] (Fig. 5).
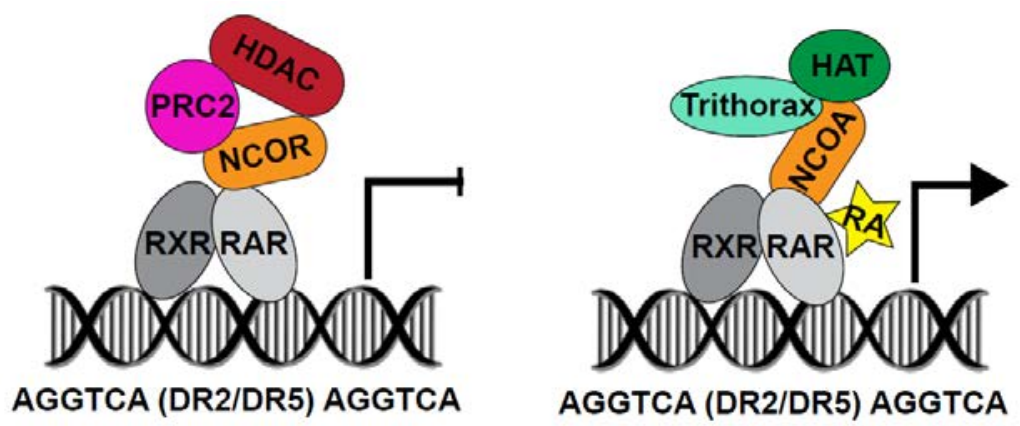

Figure 4: Retinoic acid (RA)-mediated gene regulation in development (adapted from Cunningham \& Duester 2015).

$\mathrm{D}-\mathrm{V}$ patterning is achieved by a gradient of another group of morphogens called bone morphogenetic proteins (BMPs). BMPs belong to TGF $\beta$ super family of growth factors and 
the more important ones involved in D-V patterning are BMP2/4 and BMP7 (BMP4; Drosophila Dpp orthologue). BMPs form either homodimers or heterodimers and after secretion bind a Ser/Thr kinase receptor complex on the responding cell membrane which includes two Type I (BMPR1/ACVR1) and two Type II (BPMR2/ACVR2) receptors. Upon binding of BMP, Type II receptors phosphorylate Type I receptors which, in turn, phosphorylate Smad 1/5. pSmad 1/5 then bind the common-partner Smad4 and this heterodimer complex is then nuclearized and function as a TF $[4,23,24]$. The BMP gradient along the D-V axis is achieved mainly via extracellular interactions of BMPs with their dorsally-secreted antagonists such as Noggin (Nog), Follistatin (Flst) and Chordin (Chd; Drosophila Short gastrulation (Sog)). Chd itself is subject to regulation via BMP1 (a metalloprotease) and Tolloid (Tld), which can cleave and inactivate Chordin. Sizzled (Szl), inhibits Chd cleavage by blocking the protease activity of Tld and BMP1. Twisted gastrulation (Tsg), in combination with Tld promotes cleavage of Chd but in the absence of Tld, plays an inhibitory role on BMP signaling. BMP binding endothelial regulator (BMPER) which is also known as Crossveinless-2 (CV-2) can also inhibit Chd activity (Fig. 5). This vast repertoire of Chordin regulators suggests the importance of BMPs versus Chordin interactions as major antagonists in D-V patterning [25].
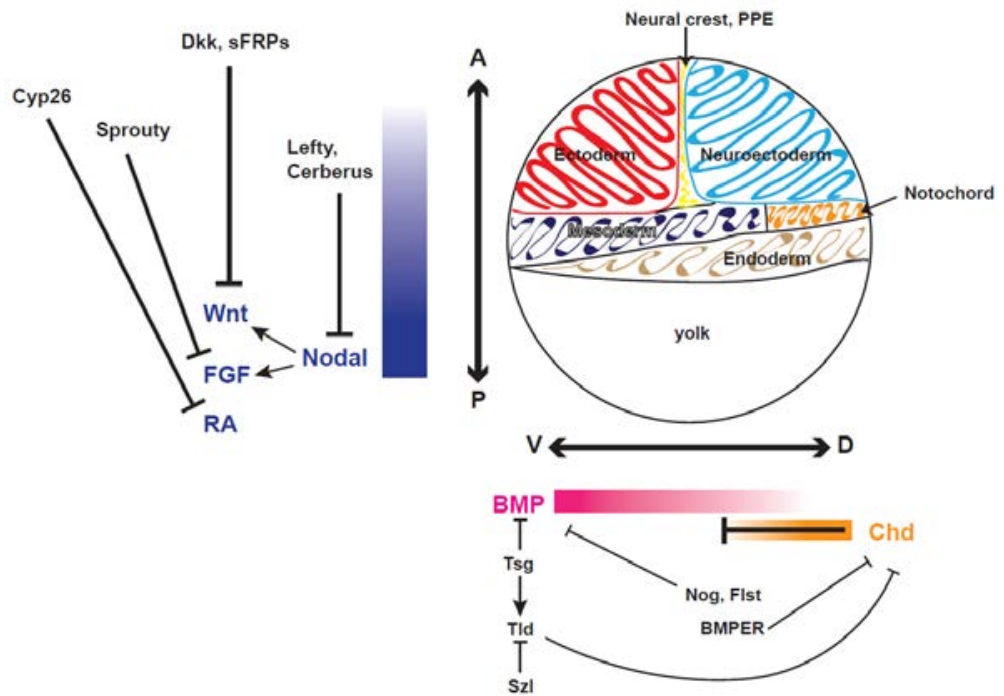

Figure 5: Zebrafish gastrula fate map with Anteroposterior (A-P) and Dorsoventral (D-V) axes being defined via the cross-regulation and interaction of different morphogens and signaling pathways (adapted from Tuazon \& Mullins 2015). 


\section{Chromatin landscape and development}

Multicellularity is achieved by the ability of different cell types to express a unique combination of genes. This complexity is not only the result of a myriad combination of signaling pathways and a vast repertoire of TFs, but also how they interact with different modification and packing states of the genomic DNA, often referred to as the chromatin landscape. Chromatin is defined as a macromolecule of packaged genomic DNA and proteins, in particular histones, though which the DNA structure, as well as its biochemistry is regulated [26]. Genomic DNA is modified, "painted", in several ways, including methylation of the DNA itself, as well as modification of the various histones. These covalent modifications act as "homing" signals for the vast array of DNA and histone-modifying proteins and TFs, and can furthermore trigger various structural changes (packaging) of the DNA.

During development, as well as throughout life, the chromatin state could be viewed as a cell type-specific mediator of gene expression, hence a determinant of cell specification and embryonic developmental program. Chromosome Conformation Capture-based techniques have shed light on how different regions of the DNA are brought into proximity, which can explain many aspects of gene regulation e.g., looping via which distant enhancers can regulate their target genes, the3D structural memory of DNA and how the nucleus is compartmentalized into distinct chromosome territories [27]. The identification of Active Chromatin Hubs (ACHs) in the erythroid-specific mouse $\beta$-globin gene, and its distant (50 $\mathrm{kb}$ ) locus control region (LCR), which is only expressed in fetal liver cells not for example in fetal brain cells [28] due to tissue-specific looping and ACH formation, emphasizes the organization of active gene-containing chromosomal regions in the interphase nucleus and its role in spatio-temporal control of gene expression. LCRs seem to have a tendency to form ACHs. LCRs could be defined as transcription activating sequences that can override chromatin position effect when randomly inserted into the genome [27]. The genome is compartmentalized into topologically associating domains (TADs) i.e., a region with increased interactions within itself but no or little interactions with neighboring regions. Each TAD has several loops to provide interactions between regulatory loci and promotors for precise gene regulation. These interactions are facilitated by cohesion protein complex and the transcription factor CTCF (CCCTC-binding factor). These two factors may also delineate neighboring TADs [27]. For example when the mouse TAD including Wnt6/Hhi/Epha4/Pax3 
locus is disrupted via CRISPR/Cas9 targeted at CTCF sites, the genes are miss-regulated and the obtained phenotype resembles human limb malformation syndromes [29]. Nucleosome composition, density and position determine the chromatin structure within each TAD. The density and positioning of nucleosomes near regulatory loci modulate gene expression. There are different histone variants and depending on which types the nucleosome is composed of, its interaction with the DNA differs, resulting in differential chromatin compactness and accessibility. Typical examples are X-chromosome inactivation (variant macro H2A) and packaging of chromatin in the sperm (variant H3.4) [26]. The epigenetic control of development is also manifested during maternal-zygotic transition (MZT) when the control of developmental program is passed form the maternally-deposited factors (proteins and RNA) on to the zygotic genome by zygotic genome activation (ZGA). In the mouse embryo, for instance, ZGA occurs right after fertilization as is the case for many viviparous animals [30]. Sperm DNA is wrapped with paternal nucleosomes/protamines, but some, not all, are replaced by maternal nucleosomes that contain the H3.3 variant. Deposition of the maternal H3.3 requires the Hira chaperone complex, which triggers rRNA transcription form zygotic genome, nuclear pore formation and the very first cell division [31]. For the ZGA to occur, H3.3 needs to be methylated at K4 as well [32]. However, some paternal histone modification are inherited from the sperm. ZGA is also marked by the recruitment of $\mathrm{CBP} / \mathrm{p} 300$ coactivator to enhancers of de novo, zygotically transcribed genes, but this occurs at different time points for different genes. Another indicator of ZGA is the altered nucleosome occupancy at the transcription start sites. ZGA is also marked by onset of TFs expression, since zygotic transcription requires TFs. In Drosophila a zinc-finger protein, Zelda, is expressed prior to ZGA and prevents nucleosome formation on its target DNA sequences, to keep them poised for transcription. Zelda does not have an orthologue in vertebrates, but Oct4 (NF-A3; POU family of TFs), which is a pluripotency TF and maternally loaded, has been demonstrated to play a very similar role in vertebrate development. Oct4 binding is facilitated by another TF complex denoted nuclear transcription factor Y (a trimer; NF$\mathrm{YA} / \mathrm{B} / \mathrm{C}$ ). The binding motif of the NF-Y complex (CCAAT) is enriched in accessible promoters that are active at early stages of development [26]. In a study of two-cell stage mouse embryos knocked-down, via siRNA, for NF-Y, the expression of many key genes was reduced, underscoring the role of this transcription factor for mouse ZGA [33]. Overall, MZT is a prolonged process that requires erasing and redecoration of DNA with different histone types and modification marks, as well as changes in chromatin state for proper activation and repression of genes over the course of development. 


\section{Chromatin remodeling via ATP-dependent enzymatic complexes}

It is not only DNA methylation and histone post-translational modification (PTMs) that determine the chromatin state and its informative architecture, but also the ATP-dependent enzymatic chromatin remodeling complexes, which contribute greatly to chromatin dynamics throughout development [34]. In mammals, the ATPase subunits of these remodelers are encoded by around 30 genes that, in most cases, do not show redundancy but rather are haploinsufficient, demonstrating the connection of their biological functions to their level of expression. Chromatin remodelers are large protein complexes, some of which are more ubiquitous while others are specific to cell types and/or developmental stages. This complexity is reflected in the evolution of these protein families from yeast to vertebrates. The complexity of vertebrate multicellularity, especially with regard to mammals, is not proportionate to an increase in the number of genes. However, vertebrate genomes have more regulatory loci compared to those of the fly or worm. Perhaps, in parallel to an increase in regulatory loci, combinatorial assembly of chromatin remodelers has evolved in more derived multicellular organism to meet the increasing demand for spatio-temporal gene regulation. As a result, while the SWI/SNF complex in yeast is monomorphic, the similar complexes in Drosophila (BAP complexes) are dimorphic and the mammalian counterparts (e.g. mouse BAF complexes) are polymorphic, meaning that there are several possible ways of assembly via several alternative subunits for such remodelers depending on the cell type and developmental time. These remodeling complexes are crucial for the establishment and maintenance of pluripotency in embryonic stem cells and can be categorized into four main families based on the sequence and structure of their ATPase subunits: SWI/SNF, ISWI, CHD and INO80 [35]. In Drosophila, the core components of Brahma-associated proteins complex (BAP) are Brahma (Brm), Moira (Mor) and Osa with Osa being replaced by BAP170 and the addition of Polybromo(BAF180) to form the polybromo-containing PAB complex (PBAP); the other orthologue of the SWI/SNF in Drosophila. In mammals, Brm and Brgl (brahma-related genel) genes code for the ATPase subunit of the SWI/SNF complex, and the two proteins are mutually exclusive in SWI/SNF complexes which is another example of combinatorial assembly [35] (Fig. 6). This temporally dynamic exchange of subunits is crucial for the transition from pluripotency to multipotency and to a differentiated state. Mouse ESCs in the ICM of the pre-implanted embryo express a unique SWI/SNF complex (esBAF), containing Brg1, not Brm, and BAF155, not BAF170 [36]. As pluripotent 
cells differentiate into neural progenitors they incorporate Brm and replace BAF60B with BAF60C [37]. This, with other subunit exchanges, creates a neural progenitor-specific npBAF complex. During the post-mitotic differentiation of neural progenitors npBAF is transformed into neuron-specific BAF (nBAF) via other subunit exchanges such as BAF45B and BAF53B instead of BAF45A and BAF53A respectively [37].

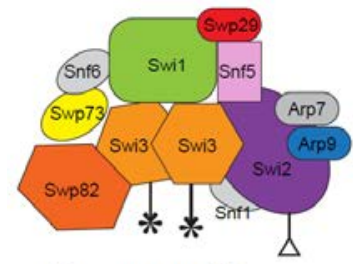

Yeast, monomorphic, transcriptional activation

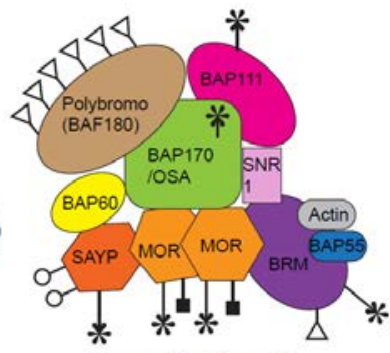

Drosophila, dimorphic, activation/repression

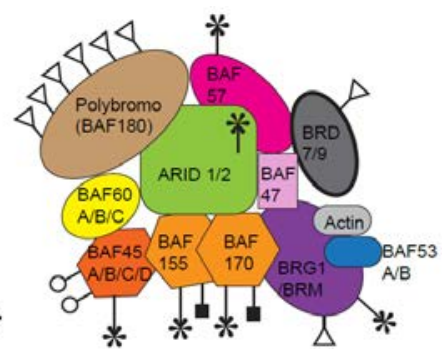

Mammals, polymorphic, activation/repression/tumor suppression

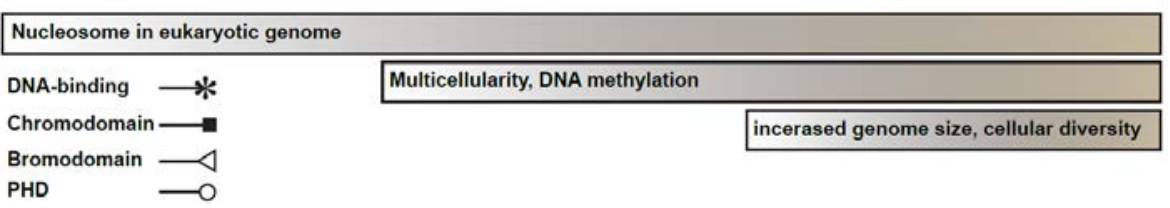

Figure6: Evolutionary diversity of SWI/SNF complexes and their cell-specific combinatorial assembly to achieve functional diversity (adapted from Ho \& Crabtree 2010).

The other family of ATP-dependent chromatin remodelers is ISWI, which in the fly, consists of three types of complexes; NURF (nucleosome remodeling factor), ACF (chromatin assembly factor) and CHRAC (chromatin accessibility complex). They all have a single ATPase subunit as their core component [35]. They are involved in higher-order chromatin structure and incorporation of the H1 linker histone [38]. The core ATPase subunit in mammals is either SNF2L or SNF2H. They have distinct roles and are incorporated into different ISWI complexes with SNF2L being part of NURF and CERF (CECR2-containing remodeling factor) while SNF2H being part of NoRC (nucleolar remodeling complex), WICH (Williams-Beuren syndrome transcription factor (WSTF) ISWI chromatin remodeling), ACF and CHRAC. However, the functions of these complexes partly overlap; NURF and NoRC are involved in gene activation and repression while ACF, CHRAC and WICH play roles in determining chromatin structure, DNA replication and chromosomal 
segregation [39]. The Chromo domain containing ATPase (CHD) family of remodelers has three sub-families, which combined include nine members; CHD1-9. CHD1 in Drosophila is needed for the maternal $\mathrm{H} 3.3$ variant to be integrated into the male pronucleus in the zygote; otherwise the paternal genome is not properly structured and fails to take part in mitosis, resulting in lethality due to the formation of haploid embryos [40]. The mammalian NURD (nucleosome remolding and histone deacetylase) complexes have either CHD3 or CHD4 as their core component and work as repressors of transcription. The Drosophila Chd7 orthologue, kismet, might be needed for transcription elongation by RNA Pol II, and there is evidence to support its role in opposing repression of target genes via the recruitment of the histone methyltransferases ASH1 and Trx [41]. The fourth family of ATP-dependent remodelers is INO80. This family is represented by the complexes: INO80 andSWR1 in $S$. cerevisiae; INO80, Snf2-related CBP activator protein (SRCAP) and p400 in mammals; INO80 and p400 in Drosophila. This family is mainly responsible for the replacement of $\mathrm{H} 2 \mathrm{~A}$ with $\mathrm{H} 2 \mathrm{AZ}$ (in mammals) or yeast Htz1 which is important for embryonic development. They also contain RuvB-like helicases (Drosophila Reptin and Pontin) which implies their roles in responses to DNA damage [42].

\section{Covalent Modifications of DNA and Histones}

One of the most studied forms of covalent DNA modifications is DNA methylation. All vertebrate and many invertebrate genomes feature DNA methylation. However, Drosophila genomic DNA is not methylated, except for at the very early stages of development [43]. Most of vertebrate DNA-methylation occurs on CG dinucleotides, often located in clusters, so-called $\mathrm{CpG}$ islands. The $\mathrm{CpG}$ islands (regions with high content of CG dinucleotides) correspond to regulatory sequences, and when methylated usually act to repress gene expression. In addition, heavy methylation of $\mathrm{CpG}$ islands can results in repressive condensation of DNA into heterochromatin [26]. DNA methylation is carried out by several enzymes, denoted DNA methyltransferases (DNMTs) including DNMT1, DNMT3A/B and the cofactor DNMT3L. The methyl group is usually provided by S-adenosyl methionine (SAM). The Ten Eleven Translocation enzymes (TETs) also oxidize 5-methyl-cytosine to 5hydroxymethylcytosine. Further oxidization by the same group of enzymes result in 5formylcytosine and 5-carboxycytosine [44]. 
Post translational modifications (PTMs) of histone proteins are also very important determinants of the chromatin state and of the regulation of gene expression. PTMs usually occur on the exposed histone protein tails of the nucleosome octamer (2 proteins each of $\mathrm{H} 2 \mathrm{~A}, \mathrm{H} 2 \mathrm{~B}, \mathrm{H} 3$ and $\mathrm{H} 4$ ), as well as on the linker histone H1 [45-48]. A vast and growing number of histone PTMs has been identified. However, for many of the histone PTMs the functional relevance is less clear. Of the histone PTMs with well-documented functions, acetylation, methylation, ubiquitination, and phosphorylation stand out.

Methylation of lysine residues is amongst the most prominent histone PTMs. Particular emphasis has been placed upon $\mathrm{H} 3 \mathrm{~K} 4 \mathrm{me} 3$, which marks active, relaxed and therefore accessible chromatin, and $\mathrm{H} 3 \mathrm{~K} 9 \mathrm{me} 3$ and $\mathrm{H} 3 \mathrm{~K} 27 \mathrm{me} 3$, which are repressive marks [46]. Histone methylation is catalyzed by histone lysine methyl-transferases (HMTs), most of which contain the SET catalytic domain, and is dynamically reversed by histone lysine demethylases (HDMTs) [48].

Acetylation of Lys $(\mathrm{K})$ residues is often associated with transcriptional activation and relaxation of chromatin as the acetylated Lys is no longer positively charged. This reaction is mediated by a large group of histone acetyl transferases (HATs) and reversed by histone deacetylases (HDACs). The most studied modification is H3K27ac, which is mediated by $\mathrm{CBP} / \mathrm{p} 300$ and is tightly associated with transcriptional activation [45].

Another type of histone PTM is phosphorylation of serine and threonine residues. Two wellknown examples are H3S10ph and H3S28ph by Aurora-B kinase, which are involved in chromosome condensation and marks mitosis [49].

Histone ubiquitination is also important for gene regulation and DNA packaging, and is mediated by ubiquitin-ligases and removed by deubiquitinases [49].

\section{The Polycomb Complex (PcG) in development}

\section{Drosophila}

The Polycomb group (PcG) and its antagonist, the Trithorax group (TrxG), were first identified in Drosophila by their opposing effects on Hox homeotic gene expression and function in determining segment identity $[50,51]$. It should be noted that PcG and TrxG are much more than mere epigenetic regulators of Hox genes. They are involved in many other 
processes such as $\mathrm{X}$ chromosome inactivation, cell cycle control, genomic imprinting, establishment and maintenance of pluripotency and its transition to multipotency and cell specification and cancer. They modify chromatin either via PTM of histones or chromatin remodeling in a context-dependent manner [52].

Although PcG is generally considered a repressive complex, it is actually represented by several different protein complexes, with different functions. The most studied complexes are Polycomb Repressor Complex 1 and 2 (PRC1 and -2), Pho-repressive complex (PhoRC), and Polycomb repressive deubiquitinase complex (PR-DUB) [52-54].

PRC1, first isolated from Drosophila embryos [55], consists of the core components dRING1 (Sce) and Psc (posterior sex comb)/Su(z)2 (suppressor of zeste 2) which are RING finger domain proteins and ubiquitylate H2AK118. The canonical PRC1 also includes Polycomb (Pc; a chromodomain, H3K24me3 binding protein), Polyhomeotic (Ph) and Scm (Sex comb on midleg) which are both SAM domain proteins. The non-canonical PRC1 consists of dRybp (RING finger and YY1 binding protein), dKDM2 (H3K36 demethylase) and other scaffolding factors (WD40 domain containing proteins). PRC1 recognizes histone methylation marks and silences the target genes (Fig. 7).

PRC2 core components include E(z) (enhancer of zeste, SET domain, H3K27 methyltransferase), $\mathrm{Su}(\mathrm{z}) 12$ (zinc finger, DNA/RNA binding), Esc/Escl (extra sex combs, WD40 domain, H3K27me binding) and Caf1-55 (chromatin assembly factor1, p55 subunit, aka Nurf55) which together deposits trimethylation marks on Lys 27 of histone H3. The associated components of PRC2 are Pcl (Polycomb-like, PHD finger domain, H3k36me3 binding), Jing and Jarid2, both of which are zinc finger proteins with H2Aub binding ability $[52,56,57]$.

(PhoRC) is composed of the zinc finger protein Pleiohomeotic (Pho) and dSfmbt protein (Scm-related gene containing four MBT domains). PhoRC can bind H3K9me1 and H4K20me2, and is the only PcG complex with sequence specificity due to its Pho component [58] (Fig. 7). There is recent evidence suggesting that Scm interacts closely with PRC1, PRC2, and PhoRC, and is necessary for the connection of these three complexes [59].

PR-DUB has the core components Calypso (ubiquitin C-terminal hydrolase) and Asx (additional sex combs), which provides binding to chromatin. PR-DUB deubiquitinases H2A which is necessary for PcG-mediated repressive function and implies that PcG function might depend on or be further fine-tuned via a delicate balance between $\mathrm{H} 2 \mathrm{~A}$ ubiquitination and de- 
ubiquitination. The other components are FoxK (Forkhead box domain), Sxc (Ogt) (super sex combs, aka O-linked $\mathrm{N}$-acetyl glucosamine transferase), dLsd1 aka, $\mathrm{Su}(\mathrm{Var}) 3-3$ which is a histone lysine demethylase and Sba (six banded), a methyl-CpG DNA binding domain protein [52].

The "docking down" of the various PcG complexes onto target DNA is still a poorly understood and intensively studies area. One insight into this issue from Drosophila revolves around Polycomb Response elements (PREs), which are specific DNA sequences to which PcG can be recruited. PREs are enriched for several TFs binding motifs such as Pho, Phol, Pipsqueak (Psq), Dorsal switch protein (DSP1), Zeste (Z), Grainyhead (Gh), Spps (KLF family), Combgap (Cg) and GAGA factor (GAF or Trl) [60].

\section{Vertebrates}

In vertebrates, especially mammals, $\mathrm{PcG}$ complexes are much more diverse, indicating yet again the importance of combinatorial assembly in a context-dependent manner for proper gene regulation in more complex organisms. With the exception of fungi and filasterea, almost all the core components of the PRC1 and PRC2 are conserved within animals and plants [52].

The core PRC1 components include RING1A/B and one of the six Polycomb group ring finger domain proteins (PCGF1-6; Drosophila Psc/Su(z)2 orthologue) for H2AK119 ubiquitination. The canonical PRC1 complexes also include the chromobox proteins (CBX2/4/6/7/8; Drosophila Pc orthologues), Polyhomeotic orthologues (PHC1-3) and SCMH1 and SCML2 (Drosophila Scm) (Fig. 7).

Non-canonical PRC1 complexes include RING1A/B, RYBP/YAF2 (Drosophila dRybp orthologue), KDM2B (H3K36 demethylase) and other WD40 domain proteins for scaffolding and functional conformation. RING1B can either bind a CBX or RYBP/YAF as they dock into the same site on RING1B. PCGF proteins are key components as they determine the E3 ligase enzymatic activity of the complex and its canonicity i.e., canonical PRC1 complexes include PCGF2/4 whereas ncPRC1 complexes can incorporate all PCGFs [61].

The mammalian core PRC2 components include EZH1/2 (Drosophila E(z)), SUZ12, EED (embryonic ectoderm development, Drosophila Esc) and Caf1 histone binding proteins RBBP4/7 (retinoblastoma binding protein 4/7). PRC2 has other accessory proteins which 
modulate its context-dependent activity including PCL1-3 (Drosophila Pcl), JARID2, AEBP2 (Adipocyte P2 Enhancer Binding Protein, Drosophila Jing) (Fig. 7).

Core PR-DUB is composed of BAP1 (breast cancer1-associated protein1; Drosophila Calypso) and Asxl 1/2 (Asx-like 1/2) with accessory proteins being Foxk1/2, Ogt1, KDM1B (Drosophila dLsd1) and MBD5/6 (methyl-CpG binding domain proteins 5/6).

In vertebrates, there are no identified PREs but unmethylated $\mathrm{CpG}$-rich DNA sequences close to transcription start sites can recruit PcG complexes, either via KDM2B (PRC1) or JARID2 (PRC2) [62-64]. It is commonly believed that PRC1, via the zinc finger domain of it KDM2B component, can bind $\mathrm{CpG}$ islands and then ubiquitinateH2A, which is later recognized by PRC2, leading to PRC2 recruitment and H3K27 trimethylation (reversed hierarchical model) $[65,66]$. However, since most KDM2B-bound $\mathrm{CpG}$ islands are not bound by $\mathrm{PcG}$, it could be the transcriptional activity of the region that also determines PcG recruitment. In the Chromatin Sampling model, $\mathrm{PcG}$ is believed to bind weakly and transiently to $\mathrm{CpG}$ islands, and if the region is transcriptionally active, stabilized PcG binding is blocked [54, 67]. In addition, similar to Drosophila, some TFs such as Rest [68], Runx1[69], E2F6 [70] and Snail [71] could be involved in PcG recruitment, even though such involvement is not global [72]. Moreover, YY1 (Yin-Yang1), the orthologue for Drosophila Pho, can recruit PcG to a subset of its target genes [73] (Fig. 7). In some cases non-coding RNAs (ncRNAs) are required to recruit PcG onto target loci in mammals $[74,75]$. The existence of different $\mathrm{PcG}$ recruitment strategies may go hand in hand with the context-specific combinatorial assembly and the choice between canonical versus noncanonical complexes, but it awaits confirmation by further studies.

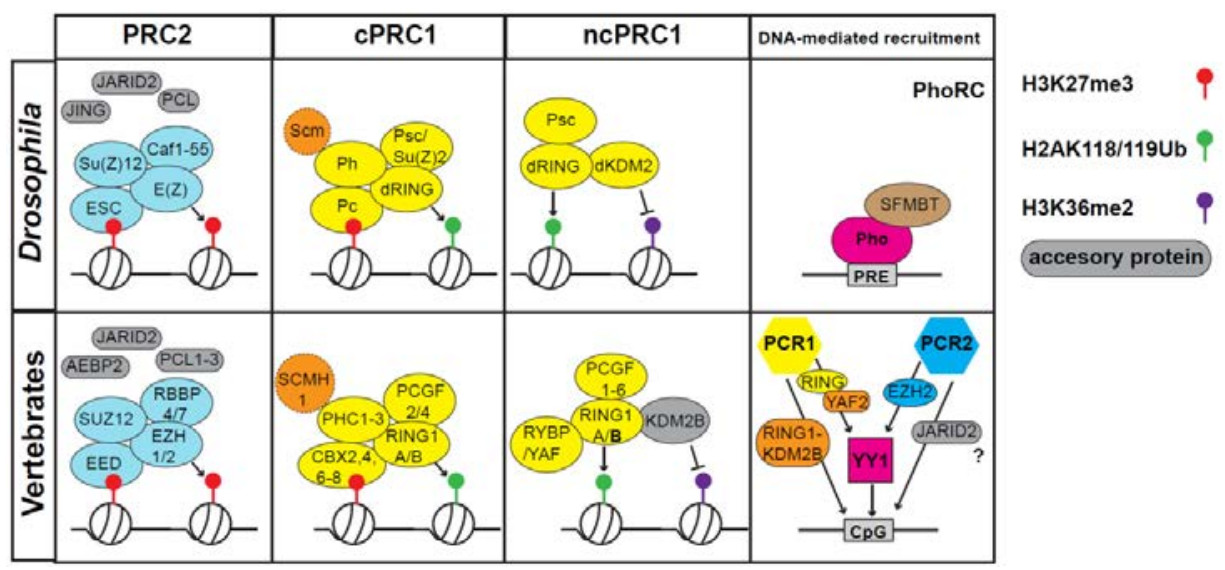


Figure 7: Compositional diversity of Polycomb Group Complex, the main histone modifications and binding in Drosophila and vertebrates (adapted from Entrevan et al., 2016 and Basu et al., 2014).

\section{Hox homeotic genes in development}

William Bateson defined "Homeosis" as the transformation of a feature of segmentally repeated structures into another [76]. The group of genes responsible for such transformations are called homeotic selector genes (Hox genes). Hox homeotic genes are evolutionarilyconserved genes which code for Homeodomain (HD)-containing TF. These TFs are important for controlling A-P patterning and segmental identification, as well as cell type diversity in the embryonic development of invertebrates and vertebrates alike. Hox genes are hypothesized to have originated from the duplication of an ancient bilaterian Hox cluster [76, 77] (Fig. 8). Gain and loss of function studies in Drosophila and mice result in altered axial segment identities or loss of body structures. Hox genes are also crucial for proper limb development [78]. The precise regulation of Hox genes occurs at both the transcriptional and translational levels. The transcriptional control is dictated, in part, by their array in the gene cluster, known as the Hox gene spatial collinearity [79, 80]. Studies in mammals have shown that the translational control can be achieved via ribosomal proteins, such as RPL38, and their interaction with unique regulons in the 5'UTRs of Hox mRNAs, which resembles viral internal ribosome entry sites (IRESs) and can confer cis spatio-temporal regulation of Hox mRNA translation [81, 82].

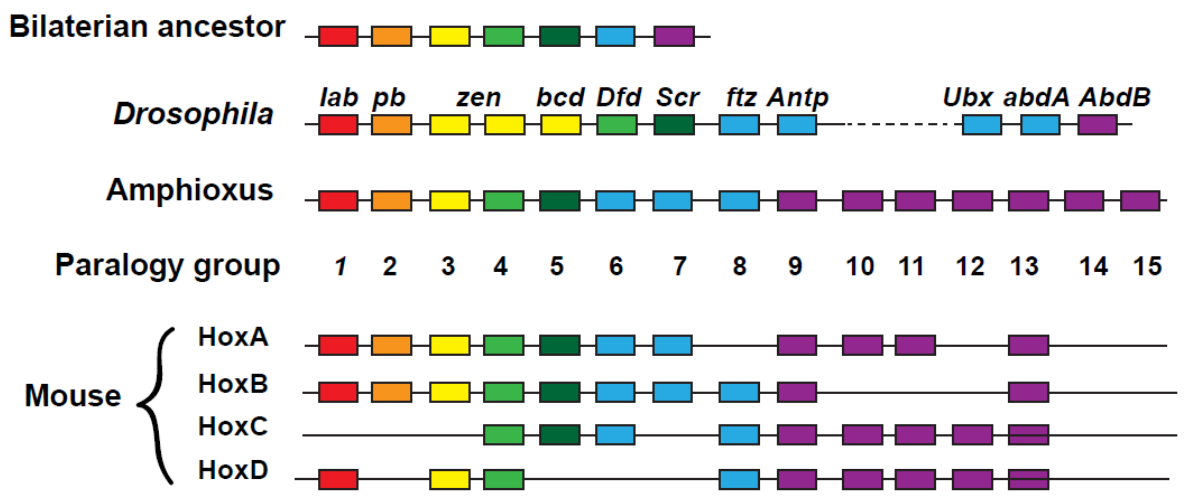


Figure 8: Hox genes in Drosophila, Cephalochordates and mammals and a possible mode of evolution from the ancestral Bilaterian cluster. In Drosophila, ftz (fushitarazu), bcd (biciod) and zen (zerknullt) are Hox-like or para-Hox genes. (adapted from Parker \& Krumlauf, 2017).

\section{Drosophila}

Hox homeotic genes are located on the 3rd chromosome and organized into two clusters; the Antennapedia complex (ANT-C), including labial (lab), proboscipedia $(p b)$, Deformed (Dfd), Sex combs reduced (Scr) and Antennapedia (Antp), and the Bithorax complex (BX-C), including Ultrabithorax (Ubx), abdominal-A (abd-A) and Abdominal-B (Abd-B). Early in development, the expression of Hox genes is established by gap and pair-rule genes, but later their spatio-temporal expression is controlled by the opposing actions of PcG (repressive) and TrxG (activating) genes [76]. In all bilateria there is no Hox gene expression in the anteriormost region of the embryo, including the CNS [83, 84], and this is largely attributed to the repressive function of PcG [85-90] (Fig. 9).
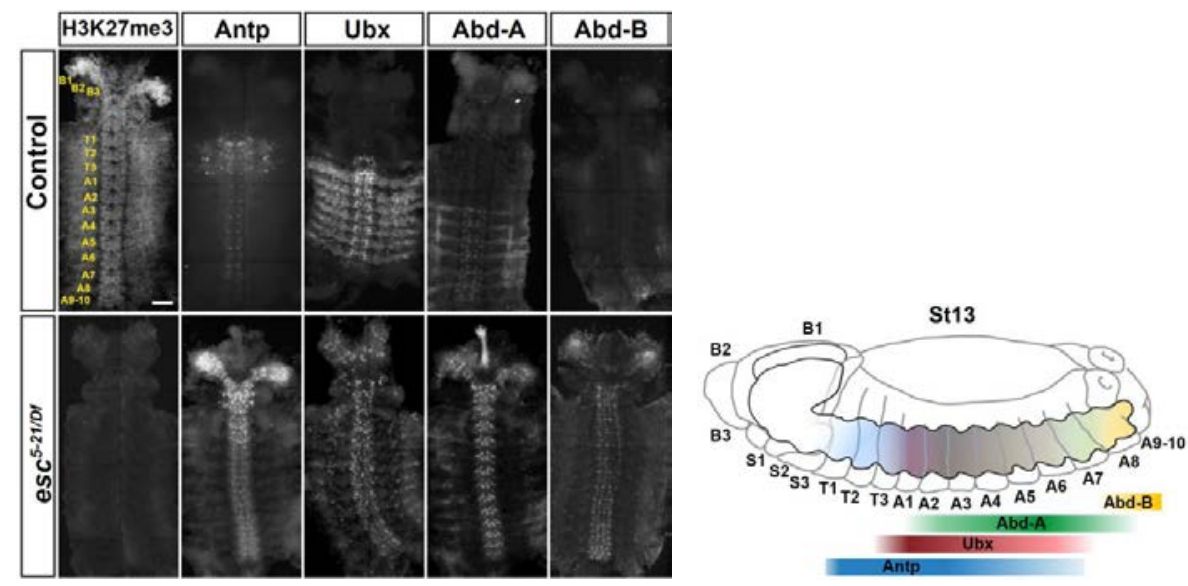

Figure 9: Hox genes expression domains along the A-P axis in embryonic Drosophila CNS and PcG function to repress them anteriorly (Yaghmaeian at al., 2018).

\section{Vertebrates}

In vertebrates, Hox homeotic genes are organized into 4 clusters denoted A, B, C and D, which have originated presumably via two successive duplications of the ancestral cluster. The numerous Hox genes of these four clusters are categorized into 13 paralogous groups 
depending on their position within the cluster $[76,78,91]$. A few studies have shown that the collinear model has temporal implications as well, meaning that the timing for the expression onset of a Hox gene is determined by its position in the cluster, with the ones near the 3 ' end being expressed earlier than the ones towards the 5' end of the cluster [92-95]. Temporal collinearity has not been reported in Drosophila. The older, classic spatial collinearity states that there is a correlation between a Hox gene's position within its cluster and its expression domain along the A-P axis in a developing embryo i.e., 3' end of the cluster is more anteriorly expressed while 5' end of the cluster is more posteriorly expressed. However, there are many exceptions or violations to these general models $[79,80]$. Much less is known about the mechanism of early Hox gene activation and regulation in vertebrates but RA-mediated regulation seems to be important. RA is a known morphogen in vertebrate embryonic development and there are RAREs in proximity of many Hox genes supporting their role in Hox gene regulation and early patterning [96] (Fig. 10).

A

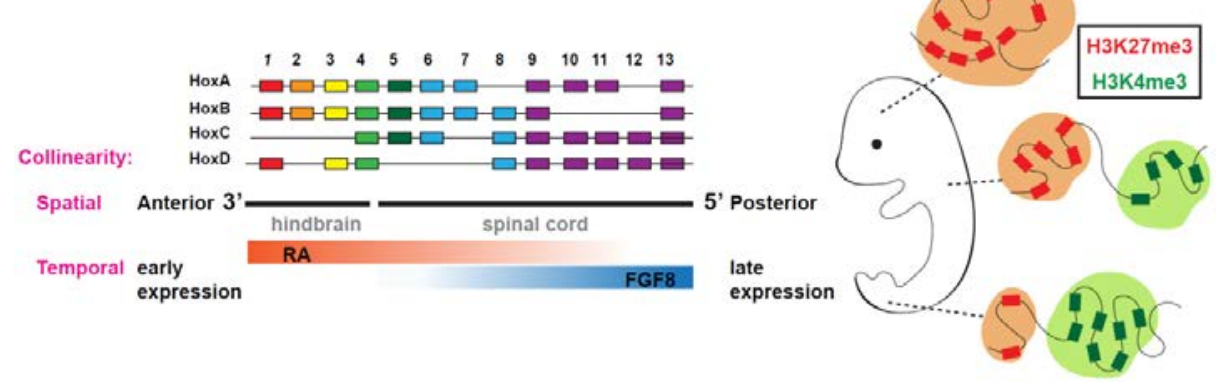

Figure 10: Spatio-temporal collinearity of Hox genes in mammals. (A) Members of the 3' end paralogy groups are activated earlier and more anteriorly in development while 5' located Hox genes are expressed later and more posteriorly. The opposing actins of RA and FGF8 are also important for spatio-temporal regulation of Hox genes, axis extension, neurogenesis and somitogenesis. (B) Spatial collinearity and chromatin structure. In the forebrain Hox clusters are compact and silent (H3K27me3), in the mid-axial levels Hox genes segregate into active, relaxed ( $\mathrm{H} 3 \mathrm{~K} 4 \mathrm{me} 3)$ chromatin compartments as well as compact, repressed ones. In posterior regions the majority of Hox genes are in active accessible chromatin compartments (adapted from Parker \& Krumlauf, 2017; Montavon \& Soshnikova, 2014). 


\section{Asymmetric versus symmetric proliferation of neural progenitors}

The defining feature of stem cells is their ability to multiply in numbers, thereby expanding the progenitor pool (symmetric division), and also to self-renew, while generating progeny with more limited competence that can finally differentiate. Self-renewal of stem cells could be intrinsic or extrinsic i.e., induced by the stem cell niche. Either way the polarity cues must be received by or bestowed upon the stem cell to establish its own polarity before the division [97].

\section{Drosophila}

In the case of Drosophila NBs, the polarity cue comes from the already polarized neuroectoderm, with its apical-basal polarity, by which Par (partitioning-defective) proteins are apically localized [97]. Drosophila NBs are stem cell-like i.e., they are multipotent cells with an intrinsic mode of asymmetric cell division. NB asymmetric cell divisions has three essential features: (1) factors that are needed for differentiation and fate determination are asymmetrically sequestered cortically during mitosis; (2) the mitotic spindle is perpendicular to the cortically sequestered determinants to ensure they are only received by the daughter cell; (3) the mitotic spindle is also asymmetric, and thereby cytokinesis results in two sister cells that are different in size; the larger, self-renewed NB and the smaller daughter cell [98, 99].

The apically-localized complexes include Par proteins (Par3/Bazooka, Par6 and aPKC) and the Gai-Pins-Loco complex. The adaptor protein Inscuteable (Insc) connects the two complexes via binding Pins and Par3 (Fig. 11). The basal localization of cell fate determinants such as Miranda and Numb, is largely mediated by the Par complex, especially via the phosphorylation activity of aPKC (atypical protein kinase $\mathrm{C}$ ) which, itself, is activated by Par6 [100]. aPKC works via Lethal giant larvae (Lgl; a tumor suppressor) to exclude basal determinants from the apical pole of the cell. The Gai-Pins-Loco is believed to control proper mitotic spindle orientation, perpendicular to the apical-basal polarity axis via a receptorindependent heterotrimeric $\mathrm{G}$ protein signaling. Pins (partner of inscrutable) and Loco (locomotion defects) are guanine nucleotide dissociation inhibitors (GDIs), and Ric8 is a cytoplasmic guanine nucleotide exchange factor which is also involved in the function of this complex. As seen in (Fig. 11), the spindle is asymmetric, being longer on the apical side with 
more astral microtubules. Pins is in contact with the protein Mushroom body defective (Mud) which is important for spindle orientation as it is a microtubule and dynein binding protein (vertebrate NuMa) and Disc-large (Dlg) as well as Khc-73 which is an astral microtubule + end protein.

There are two basal protein complexes. One consists of Miranda, an adaptor protein, which binds Brat (Brain tumor; a translational repressor), Prospero (Pros), a HD transcription factor and the dsRNA-binding protein called Staufen, which binds pros mRNA. The second basal complex includes Numb (Notch antagonist which binds NICD) and Pon (partner of Numb). After division, in the daughter cell, Mira is degraded, Pros is released and nuclearized to, in concert with Brat and Numb, promote cell differentiation and repress self-renewal. Mutations of several components of asymmetric cell division machinery have been linked to tumorigenesis [101]. Interestingly, other studies have demonstrated a link between factors involved with cell cycle progression, such as Aurora kinase A and Polo kinase and the asymmetric cell division machinery. These two kinases have been shown to regulate cell cycle progression partly via orientation of mitotic spindle as well as Numb asymmetry, which in turn affects Notch pathway. Polo regulates Numb asymmetry via phosphorylation of a key serine residue of Pon [102-104].

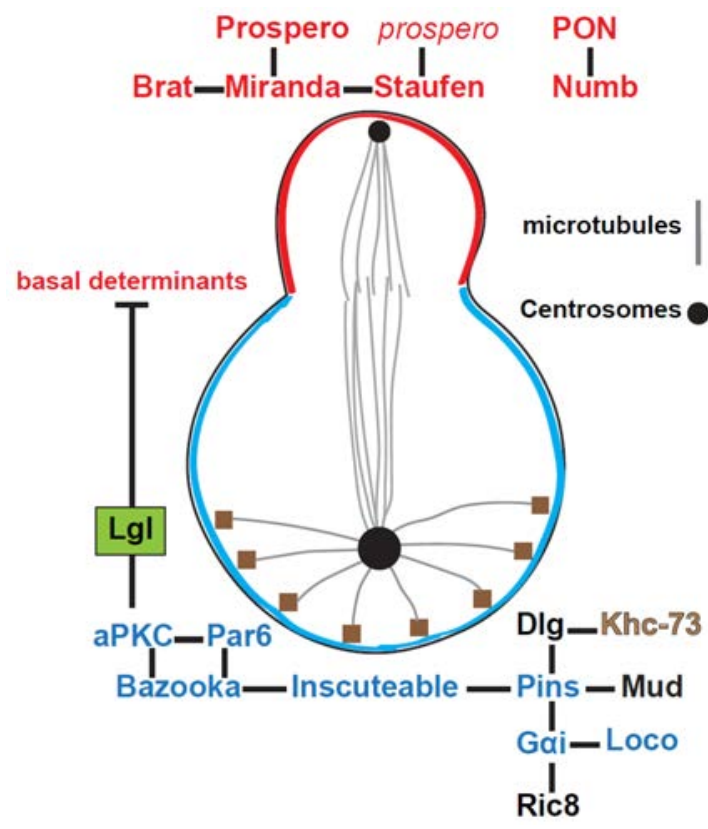

Figure 11: Neuroblast apical and basal complexes in asymmetric division. Asymmetric segregation of these components determine either the self-renewing NB fate or that of the daughter cell (adapted from Chia et al., 2008). 


\section{Vertebrates}

Vertebrate neural progenitors also undergo both symmetric and asymmetric cell division. Preceding neurogenesis, neuroepithelial cells (NECs) in the neural tube divide symmetrically to expand the progenitor pool. In the ventricular zone (VZ) of the developing cortex during later stages of neurogenesis, radial glial cells (RGCs), another type of neural progenitors derived from NECs, divide symmetrically to give rise to either two neurons or two glial cells. This type of late symmetric division is called self-consuming. Early in neural development, RGCs in VZ divide asymmetrically to self-renew and produce a neuron. RGCs can also selfrenew and produce an intermediate progenitor (IP) via asymmetric division. The IP, in the sub-ventricular zone (SVZ), divides symmetrically to generate two neurons. In mammalian neocortex, RGCs can divide asymmetrically to produce an IP and a basal radial glial cell/basal progenitor (bRG/bNP). Basal progenitors lose their apical connections but retain their basal podia connection to the basal lamina of the outer cortical plate. bRGCs, in turn, can divide asymmetrically to self-renew and produce an IP. These mammalian-specific divisions can partly underlie the boosted cortical expansion of cell types and numbers in more-derived organisms [105]. Neural progenitors (NECs \& RGCs) are polarized cells with their apical pole close to the ventricle of the developing cortex or spinal cord and their basal pole connected to the pial-basal membrane. The have adherence junctions consisting of cadherins and catenins in their apical membrane which is connected to the cellular actins. The Par complex is also sequestered in the apical pole. The centrosome is also located at the apical pole in these cells, and functions as a basal body for the nucleation of the primary cilium. Primary cilium is formed during the transition of NECs to RGCs, and is crucial for the apical-basal polarity in RGCs. Symmetric division of neural progenitors (NECs \& RGCs) early in development is tightly connected to the positioning of LGN-Gai-NuMa complex in the lateral membranes of the cell, and its connection to astral microtubules by Dynein binding. The astral microtubules anchor the mitotic spindle to the lateral membranes and their positioning, together with that of the centrosomes, is pivotal for the symmetric division. LGN is the vertebrate orthologue for Drosophila Pins. It is a G-protein signaling modulator. In this mode of symmetric division the Par complex seems to be inherited equally by the two sister cells. The fates of the sister cells arising from the asymmetric division of RGCs depend on the orientation of the mitotic spindle relative to the epithelium plane and how the apical and basal processes are inherited by the two sister cells. The basal process can be inherited by both sister cells or only one. The ability of the cell to grow is connected to inheritance of the 
basal process, and hence determines self-renewing RGC versus IP/neuron fate. It furthermore seems as if the inheritance of both apical and basal processes is necessary for the sister cell which is to maintain RGC identity [105, 106]. Resent evidence suggests that the different fates of sister cells following cell division is determined by asymmetric centrosomes positions and ciliogenesis. The older, larger, mother centrosome is usually inherited by the cell that is to retain RGC/stem cell identity [107]. The mother centrosome can reform the primary cilium much faster than the daughter centrosome inherited by the other sister cell. Besides, the ciliary membrane which is anchored to the mother centrosome, is endocytosed during mitosis and is coinherited with the mother centrosome by the self-renewing sister cell [108]. The other sister cell which has inherited the daughter centrosome also regrows the cilium but on its basolateral membrane, not the apical one, which marks the cell for differentiation and later detachment from the apical belt and migration [109] (Fig. 12). This temporal difference that results from asymmetric centrosome inheritance causes the cell with the mother centrosome and apically-located primary cilium to respond differently to signals and cues from the cerebrospinal fluid (CSF) such as Shh and IGF-1 [110]. Staufen, a dsRNAbinding protein, is also asymmetrically inherited by the differentiating sister cell. Staufen binds a number of mRNA transcripts for cell cycle exit and differentiation including Trim32 (Drosophila Brat1). Hence, many aspects of asymmetric division machinery is conserved from invertebrates (Drosophila) to mammals (mouse) yet, there are differences in the detailed molecular and structural mechanisms utilized by different species.
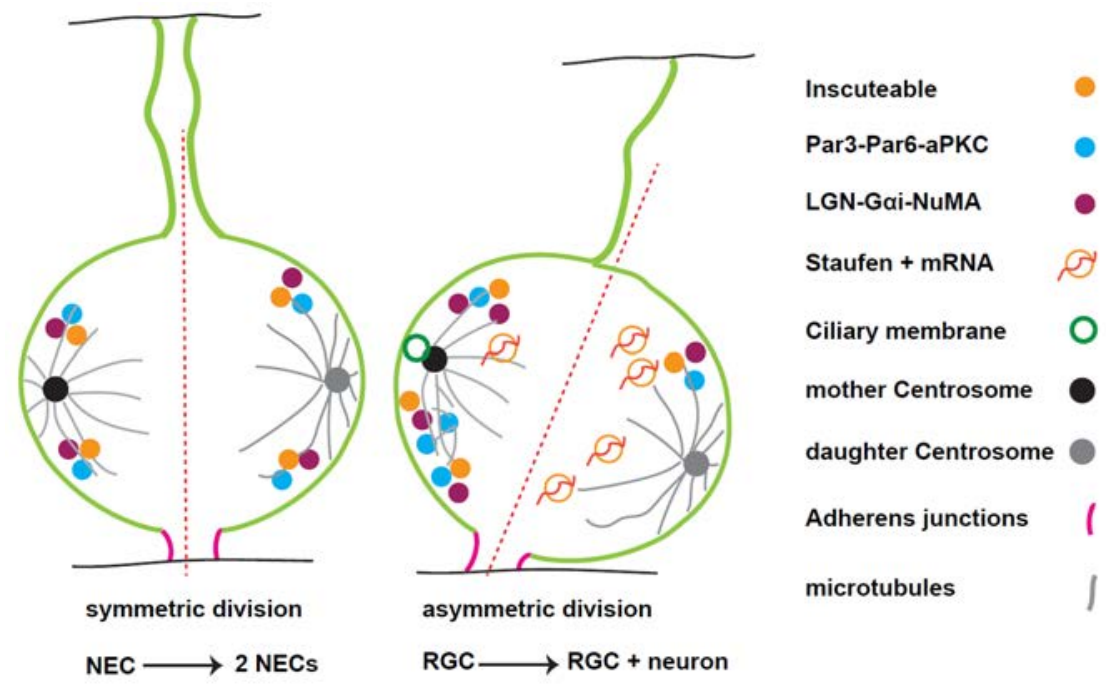
Figure 12: Symmetric and asymmetric cell divisions of neural progenitors (NECs/RGCs) in vertebrate neurogenesis, determined by spindle orientation, inheritance of cell fate determinants and inheritance of mother centrosome together with the ciliary membrane (adapted from Paridaen \& Huttner, 2014).

\section{Drosophila CNS development}

The central nervous system (CNS) in Drosophila is generated from the neuroectoderm. The neuroectoderm is the neurogenic region of ectoderm (neuroepithelium), which is formed during gastrulation when mesoderm invaginates connecting the two lateral parts of neuroepithelium [111] (Fig. 13).
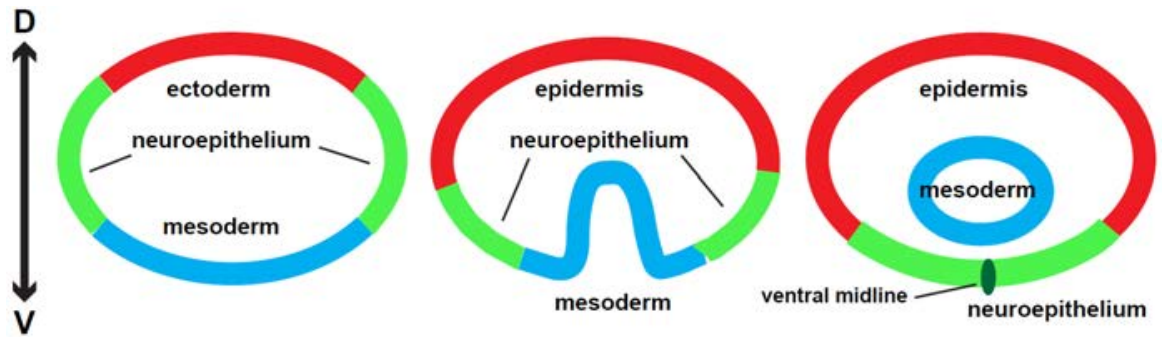

Figure 13: Gastrulation of Drosophila embryo. Invagination of ventral mesoderm connects the two lateral neuroepithelial regions to form the neuroectoderm from which the future NBs delaminate (adapted from Mieko Mizutani \& Bier, 2008).

The brain and the ventral nerve cord (VNC) comprise the CNS, and are generally considered to correspond to the vertebrate brain and spinal cord, respectively. The brain is subdivided along the A-P axis into three segments i.e., the protocerebrum (PC/B1), deutocerebrum $(\mathrm{DC} / \mathrm{B} 2)$ and tritocerebrum (TC/B3). The $\mathrm{VNC}$ is divided into three sub-esophageal segments (S1-S3), three thoracic segments (T1-T3) and 10 abdominal segments (A1-A10). Since the CNS has bilateral symmetry, each segment can be further subdivided into two hemisegments. Each VNC hemisegment is generated by delamination of around $30 \mathrm{NBs}$, by average, and they divide to form their lineages, which differentiate for become nervous tissue cells i.e., neuron and glia. In the brain hemisegments combined (B1-B3) about 106 NBs delaminate from the anterior neuroectoderm. Recently, another 8 NBs which divide in Type II mode (see 
below for division modes) have been identified in the embryonic brain $[112,113]$, so in total there are 114 NBs in the B1-B3 hemisegments.

In the Drosophila CNS, NBs delaminate in five sequential waves from embryonic stage 8 until stage 11, with the exception of Type II NBs which presumably delaminate later, to divide asymmetrically and form their specific lineages. NB delamination, in both the brain and VNC involves the interactions of Delta and Notch in a process called "lateral inhibition" [114]. Each NB has a unique identity based on its position (row and column; a Cartesian-like coordinate system) and expresses a unique combination of markers. For instance, NB5-6T is located in row 5, column 6 in a thoracic segment, while NB4-2A is in row 4, column 2 in an abdominal segment. By the end of neurogenesis, some 1,200 NB have generated the Drosophila CNS, which consists of about 5000 cells in the brain and about 10,000 cells in VNC (Fig. 14).

A

\section{embryonic Drosophila CNS}

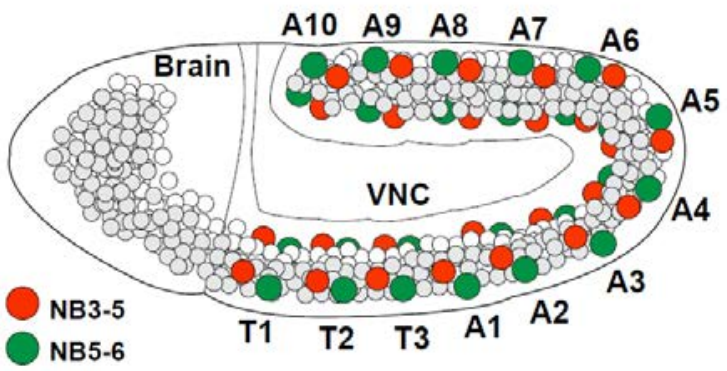

B

\section{Hemisegment}

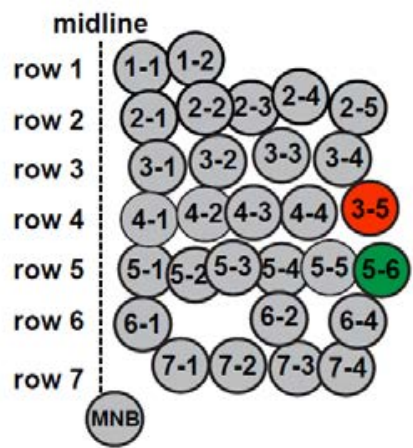

Figure 14: (A) Drosophila embryonic CNS, subdivided into the brain and ventral nerve cord (VNC). The VNC is further subdivided into 3 sub-esophageal, 3 thoracic and 10 abdominal segments along the A-P axis. Each segment at the midline can be divided into 2 hemisegments. The brain contains about 5,000 cells and the VNC around 10,000 cells. (B) One hemisegment, showing the position (row-column) of the NBs. In red is the NB3-5 and in green is the NB5-6 (adapted from Monedero et al., 2017 and from http://uoneuro.uoregon.edu/doelab/nbmap.html). 
Since the CNS is of ectodermal origin, the same hierarchy of factors that regulate the entire body plan along the A-P axis are also at work here. Maternal morphogens (bicoid, nanos and caudal) first regulate the expression of the gap genes, including oskar (osk), hunchback $(h b)$, Kruppel (Kr), knirps (kni), giant (gt), tailless (tll), unpaired (upd) and hopscotch (hop). The spatially-defined expression of gap genes along the AP axis and their cross-regulation is followed by the onset the pair rule genes including even-skipped (eve), hairy (h), runt (run), fushi-tarazu (ftz), paired (prd), odd-paired (opa), odd-skipped (odd) and sloppy-paired (slp 1/2). Expression of the gap genes and pair rule genes is transient and is down-regulated during gastrulation, thus considered as pre-patterning. Upon gastrulation another group of genes, the segment polarity genes, are expressed within the segmented regions along the A-P axis to determine intra-segment identities. The segment polarity genes include engrailed (en), gooseberry (gsb), wingless (wg), armadillo (arm), cubitus-interruptus (ci), fused (fu), hedgehog $(h h)$, naked $(n k d)$, patched (ptc) and dishevelled (dsh) $[115,116]$. The graded and spatially-defined expression of the Hox genes along the AP axis, which is initially established by the gap and pair-rule genes, also acts to define segment identity [117].

\section{Modes of daughter cell division}

There are three types of division modes identified in the Drosophila embryonic CNS. Type I, by which an NB divides asymmetrically to bud off one daughter cell that divides only once to generate two neurons or glia. Type 0 , by which the NB divides asymmetrically to self-renew and generate a daughter cell which does not divide but differentiates into a neuron. Type II, by which the NB divides to self-renew and bud off a daughter cell that divides multiple times [118-122] (Fig. 15). Embryonic Type II NBs have been recently identified in the brain and have been shown to contribute tremendously to the adult CNS $[112,113]$.

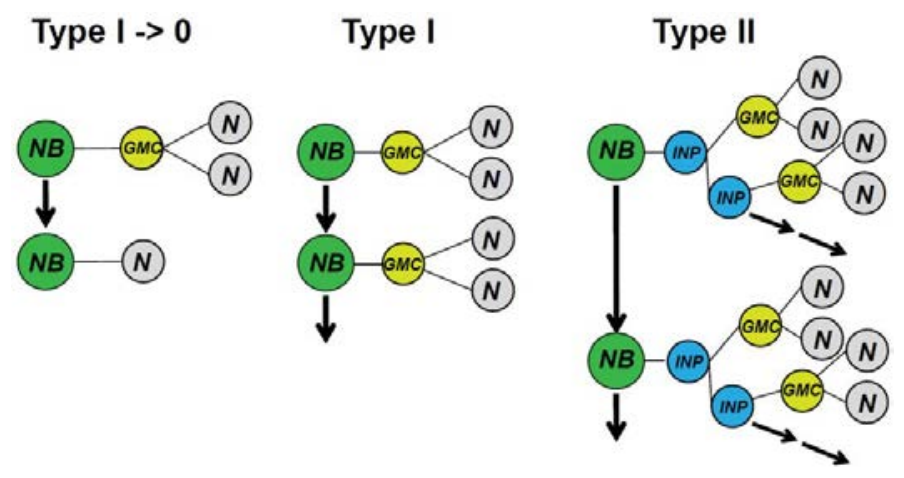


Figure 15: Cartoons demonstrating different modes of daughter cell division and the Type I $>0$ switch. Daughter cell proliferation mode has an important impact on lineage size, total cell number and anterior expansion of Drosophila embryonic CNS. NB: neuroblast; GMC: ganglion mother cell, aka, daughter cell; INP: intermediate neural progenitor; N: neuron/glia.

\section{Temporal progression of neuro-development}

As neural progenitors (NBs in fly) divide to generate the CNS, their developmental competence and that of their daughter cells change over time. The temporality of development is pivotal in the cell fate specification and neural diversity. Studies in Drosophila have identified a hierarchy of transcription factors, expressed sequentially in NBs which, with other factors such as Hox genes, determine their temporal identities and the fate of their progeny [123]. These factors include; Hunchback (Hb), Kruppel (Kr), Pdm (Nubbin/Pdm1 and Pdm2), Castor (Cas) and Grainy head (Grh) [124]. Depending on the temporal window in which a daughter cell (GMC or neuron/glia) is born, its terminal cell fate is specified. How is this temporal transition achieved? The answer is that the temporal factors cross-regulate each other i.e., each temporal factor activates the next one in line and represses the previous one. It also, in most cases, represses the factor next to the one it has activated. This transition is also observed in vitro for isolated, cultured NBs $[125,126]$. There are subtemporal factors which delineate a competence window into smaller windows. In NB5-6T, Cas activates Grh, but also a sub-temporal cascade including squeeze ( $s q z$ ) a Kruppel C2H2type zinc-finger protein, and its co-factor $n a b$, a NGFI-A-binding protein and Seven up (Svp) an orphan nuclear hormone receptor TF. Towards the end of its lineage, NB5-6T switches from the Type I division mode to Type 0, and generates four Apterous (Ap) neurons [127]. The sub-temporal cascade together with $\mathrm{Kr}$, ensure the proper identities of these four neurons. Two of these four neurons; Ap1 and Ap4 are neuropeptidergic (Nplp1 and FMRFa respectively), in which Svp is not expressed. The late expression of $\mathrm{Kr}$, via Cas, represses Svp to ensure the commitment of the last born Ap cell to the neuropeptidergic cell fate [128] (Fig. 16). 


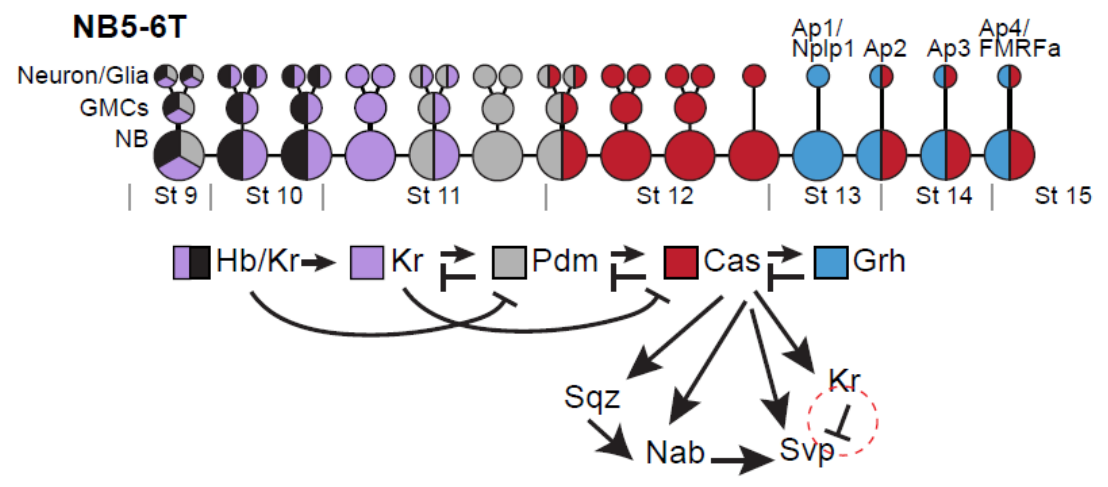

Figure 16: The temporal progression in NB5-6T lineage. Interactions of the temporal factors determine the cellular identities. In the Type 0 window, sub-temporal factors with the late onset of $\mathrm{Kr}$ ensure proper identification of the Ap cluster cells (adapted from Baumgardt et al., 2014 and Stratmann et al., 2016).

The NB lineage progression comes to an end via one of three mechanisms: 1) Cell cycle exit followed by quiescence e.g., NB3-3T. 2) Cell cycle exit followed by programmed cell death (PCD) e.g., NB5-6T. 3) PCD e.g., NB7-3 [122, 123, 127, 129, 130] (Fig. 17).

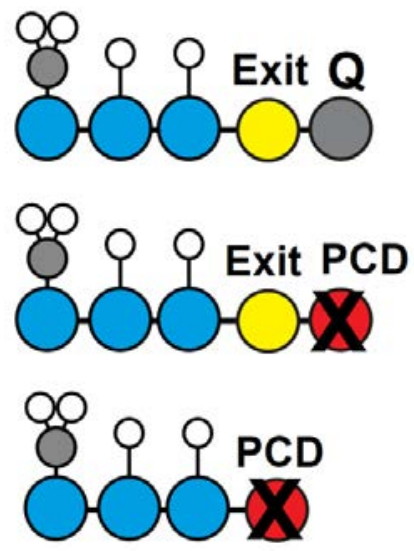

Figure 17: Cartoons for different modes of termination of NB progression. In more anterior CNS, many NBs undergo quiescence by the end of embryonic neurogenesis. Exit: cell cycle exit; PCD: programmed cell death; Q: quiescence.

\section{Lineage trees and markers}

The time of NB delamination from the neuroectoderm, its position with regard to the row and column it is assigned to, and the unique profile of gene expression determine its identity, lineage size and the types of progeny it will generate with regard to cell specification and terminal fate selection. Delamination occurs in five consecutive waves denoted S1 to S5 from 
stage 8 to stage $11[5,131]$. Early delaminating NBs generally produce larger lineages (10 to more than 20 cells) than late delaminating ones ( 2 to 10 cells).

One of the advantages of using Drosophila as a model for neural development is the resolution that its vast genetic tool kit provides, such that in many cases, especially in VNC, one single NB and all its progeny can be traced and studied. There are restricted reporter transgenic constructs that label single or multiple NBs and their progeny e.g., lbe $(K)$ GFP/lacZ for NB5-6, [127, 132], eagle-GAL4 (eg) for NB3-3 and NB7-3 [133, 134] and ham-GFP or ham-GAL4 for NB3-5 [130] (Fig. 18).

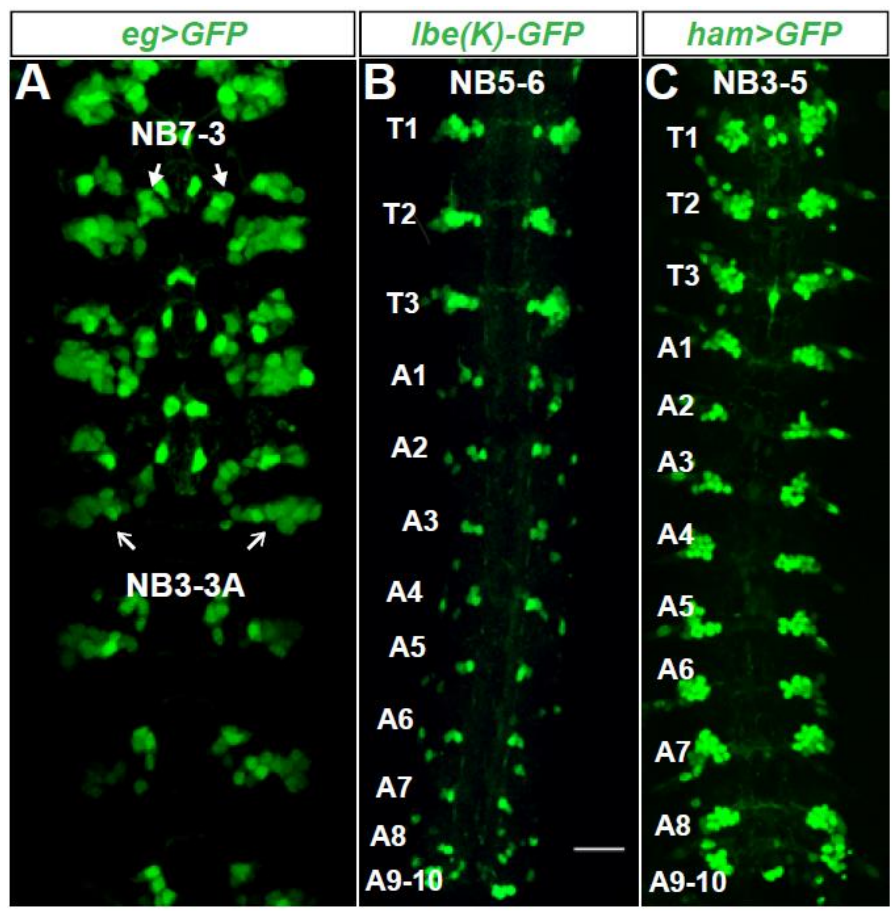

Figure 18: Transgenic reporter lines to identify different lineages in Drosophila embryonic VNC.

\section{Vertebrate CNS development}

How exactly the neural plate in vertebrates gives rise to the CNS is much less understood, but early in vertebrate development, the notochord induces the ectoderm to obtain neural fate which becomes the neural plate. Subsequently, the neural plate is patterned, and following 
neurulation, it develops into the neural tube [105]. The notochord is of mesodermal origin and is a structure in the middle of the D-V and L-R axes, which is common to the Chordata phylum. The notochord secretes factors important for fate determination (neural fate in ectoderm), as well as pancreatic fates, artery versus vein fates and other cell types in somites. Additionally, it provides a scaffold structure and functions as an axial skeleton until it is replaced by vertebrae. In higher vertebrates it is then degraded, but in primitive fish and lampreys it is maintained throughout life [135] (Fig. 19).
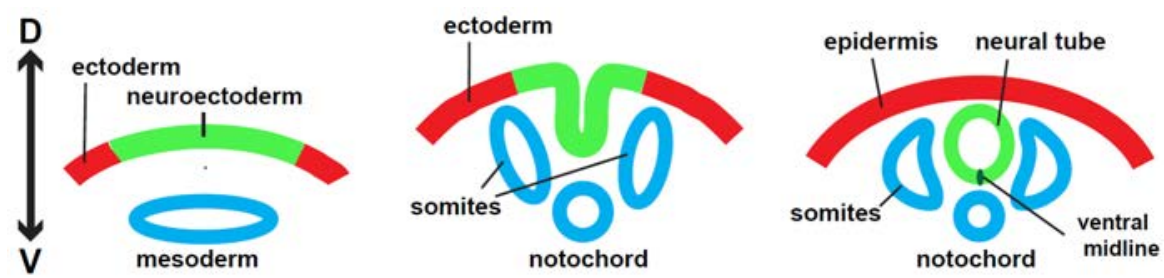

Figure 19: Gastrulation, followed by neurulation in vertebrate embryonic development. The invaginated mesoderm becomes the notochord and somites. The neural tube gives rise to the CNS (adapted from Mieko Mizutani \& Bier, 2008).

The hall mark of neurogenesis in vertebrates is the transition of neuroepithelial cells (NECs) into radial glial cells (RGCs), which is accompanied by the loss of tight junctions and appearance of adherence junctions on their apical membrane. RGCs express GLAST (glutamate-aspartate transporter) and BLBP (brain lipid-binding protein). In the mouse embryo this transition occurs around E9-E10 and the first neurons are born between E9 and E10 [136] (Fig. 20). The interactions of dorsally-secreted morphogens, such as Wnt and BMPs with the ventrally-secreted morphogens, such as Shh control D-V patterning of the developing CNS. Shh induces Gsh1/2(Drosophila ind) expression in ventral telencephalon, and Nkx2.1 (Drosophila vnd) in the medial-ventral regions (Drosophila vnd). Nkx2.1, in turn, activates the expression of LIM homeobox Lhx6, which is involved in terminal differentiation. Gsh1/2, in turn, activates the expression of the bHLH TF Ascl1 and the homeodomain proteins Dlx1/2, which are all necessary for neuronal differentiation in ventral telencephalon. Shh also opposes the repressive activity of Gli3. Gli3, when acting as a repressor, is required for dorsalization, and thus Shh and Gli3 interaction defines D-V 
identities. Dorsally, Wnt activates Pax6 and Ngn1 (Neurogenin1) expression, which together with Ngn2 are the main drivers of neurogenesis in the cerebral cortex. The dorsal proneural genes (Ngn1/2) and the ventral proneural gene (Ascl1) both trigger neurogenesis and progeny migration, but also suppress gliogenesis. However, being spatially distinct implies their roles in induction of spatially distinct identities. Ngn1/2 together with Pax6 are involved in specification of glutamatergic neurons of cerebral cortex, while Ascl1 together with Dlx 1/2 contribute to GABAergic neuron specification in ventral telencephalon, including basal ganglion neurons and cortical interneurons [136].

Notch signaling is also crucial for vertebrate neurogenesis. Delta or Jagged which are Notch ligands, bind the Notch receptor on neighboring cells. Activated Notch receptor is then cleaved and the cytoplasmic domain is released (NICD). NICD is nuclearized and activates HES gene transcription. HES genes (Drosophila hairy and Enhancer of split $(E(s l p))$ code for bHLH transcription factors that repress proneural genes such as Ascl (Achaete-scute-like) and Ngn (Neurogenin), thereby keeping the cell in a proliferative, self-renewal state. Hence, following RGC division, the asymmetric inheritance of Notch pathway components between the two sister cells, renders one with higher Notch signaling, which is the cell that maintains RG cell fate, while the other cell, with high Delta expression, shows high levels of proneural genes and differentiate $[137,138]$. In the mouse developing neocortex, differentiating cells and IP cells express Delta, Jagged and Mindbomb (Mib), an E3 ubiquitin ligase necessary for ligand maturation and turn-over, signal back to RGCs to maintain their Notch activity.

Along the A-P axis, opposing gradients of morphogens such as RA and FGF8 help to determine the spatial identities of neural progenitors and their progeny during neural development. RA, which is mainly produced by trunk mesoderm, has a two-tailed gradient, with its peak levels around the thoracic segments, gradually diminishing anteriorly towards the hindbrain and posteriorly towards the posterior abdominal or caudal segments. RA is kept out of the brain and the most-posterior regions via the antagonistic effects of Cyp26, a cytochrome P450 enzyme. Graded levels of RA is believed to modulate Hox gene expression along the A-P axis which are also pivotal in cell fate determination and proliferation control [136]. 


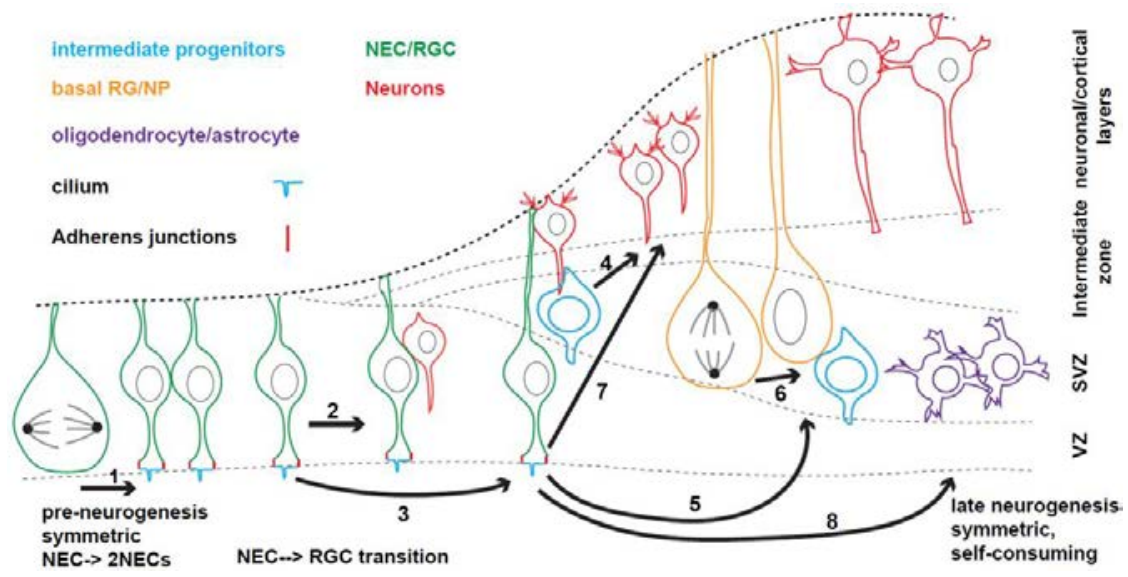

Figure 20: Neurogenesis and different division modes of neural progenitors (arrows) in vertebrate embryonic CNS. (1) NEC->2NECs; symmetric divisions to expand progenitor pool, which occur very early in neurogenesis. (2) RGC->RGC+ neuron. (3) RGC-> RGC + IP. (4) IP-> 2 neurons. (5) RGC-> bNP + IP. (6) bNP->bNP + IP. (7) RGC-> 2neurons. (8) RGC-> 2macroglia. Divisions 7 and 8 are symmetric, self-consuming and occur at the end of neurogenesis. Division modes involving IPs and bNPs usually occur in mammalian neocortex. VZ: ventricular zone; SVZ: sub ventricular zone. (adapted from Paridaen \& Huttner, 2014).

\section{Temporal progression of neuro-development}

There is a strong correlation between cell type specification and its time of birth. For example neurons in the deep layers of cortex are born first while neurons in upper layers are born later with the outer-most neurons being born latest [139]. This strategy is employed in other parts of the vertebrate CNS such as the spinal cord [140]. The molecular details of temporal progression for neural progenitors and how this affects their competence and progeny overtime, is intensively and extensively studied in Drosophila [141, 142], but such profound understanding in vertebrate model systems requires higher lineage resolution and better marker combinations. Yet, the inside-out mode of neurogenesis in vertebrates, with progenitors dividing in $\mathrm{VZ}$ or SVZ and the layered organization of the developing neocortex and later the adult cortex, combined with identification of certain transcription factors as layer-specific determinants, has helped resolve the temporality of neurogenesis for some neuronal populations. While all cortical progenitors are Sox2+ and Pax6+, layer VI neurons 
are Sox 5+/Tbr1+, layer V neurons are Fezf2+/Ctip2+ and layer II/III neurons are SatB2+ [143]. It is noteworthy though that the Sox $2+/ \mathrm{Pax} 6+$ progenitors that give rise to these neurons are themselves subject to temporal progression and change, and the mere coexpression of two markers does not render them static. Interestingly, the layer-specific determinants cross-repress each other to ensure the proper spatio-temporal identification of neurons in each layer [136]. Additionally, the switch from the neurogenic phase to gliogenic phase is temporally controlled, whereby in early neurodevelopment neural progenitors such as RGCs, directly or indirectly via IPs, generate neurons while toward the end of neurodevelopment they give rise to macroglia (oligodendrocytes $\&$ astrocytes) via symmetric, self-consuming divisions [105].

\section{Cell cycle control in CNS development}

The eukaryotic somatic cell cycle is a process through which a cell grows, duplicates its genetic material (DNA) and then divides. The cell cycle consists of five phases including synthesis of DNA (S), Mitosis (M), two Gap phases (G1 \& G2) between S and M and the quiescence phase (G0). The key components of the cell cycle machinery are heterodimeric proteins which include a Cyclin and a Cyclin-dependent kinase (Cdk). Cyclins are usually expressed periodically, and the binding of the specific Cdk makes the complex active and functional [144]. In Drosophila, Cdk1 and Cdk2 are essential genes. Cdk2 acts with CycE to promote $\mathrm{S}$ phase, while Cdk1 acts with either $\mathrm{CycA}$ or $\mathrm{CycB}$ for mitosis [145-148]. Another major Cyclin-Cdk dimer is CycD-Cdk4, which in mammals gates the early steps of G1, while in Drosophila it appears to control cell size.

To further regulate the kinase activity of the Cyclin/Cdk dimer, these heterodimers are normally kept inactive in the cell by binding of an inhibitory protein (CKI) such as Dacapo (mammalian p21/p27/p57) and Rux in Drosophila, or via phosphorylation by Wee1/Myt1 kinases. The inhibitory phosphorylation of Wee1/Myt1 could be reversed by Cdc 25 phosphatase family members such as Drosophila String (Stg). The G1/S transition requires the active E2f/Dp transcription factor heterodimer which induces transcription of $C y c E$ and $C y c A$ among other target genes. The tumor suppressor retinoblastoma-family protein (Rbf) binds E2f/Dp and renders it inactive. In order for E2f/Dp to be released and activated, Rbf needs to be phosphorylated by $\mathrm{CycD} / \mathrm{Cdk} 4$ as well as $\mathrm{CycE} / \mathrm{Cdk} 2$. Each transition along the cell cycle is monitored and regulated by different checkpoints. The G2/M checkpoint ensures 
that the DNA is properly duplicated and is intact. $\mathrm{CycA}$ and $\mathrm{CycB}$ active heterodimerism with respective Cdks is key for mitosis entry [149] (Fig. 21).

Many studies have demonstrated the link between cell cycle and development regarding fate determination and differentiation. The cell cycle also comes in different flavors throughout embryonic development. Early in development the cell cycle is merely S and M phases but as mid-blastula transition is reached, G2 is incorporated. Towards the end of the development G1 is also added. Accumulating evidence has shed light on the role that cell cycle regulators play in striking the balance between neural progenitor self-renewal and differentiation, thus connecting the cell fate decisions to cell cycle. The $\mathrm{p} 73$ protein, which is a tumor suppressor, not only acts as a cell cycle factor by transcriptional activation of $\mathrm{p} 21 \mathrm{Cip} 1$ and therefore attenuation of proliferation but also works as a cell fate determinant for Cajal-Retzius neurons of hippocampus [150]. Rb has also been implied to function as a differentiation factor as well in mouse neural development [151]. Another example is the role of Xenopus p27Xic1 in retinal glial cell differentiation [152]. This is a cross-regulation though and developmental morphogens including Shh, Notch and EGF can also affect the cell cycle.

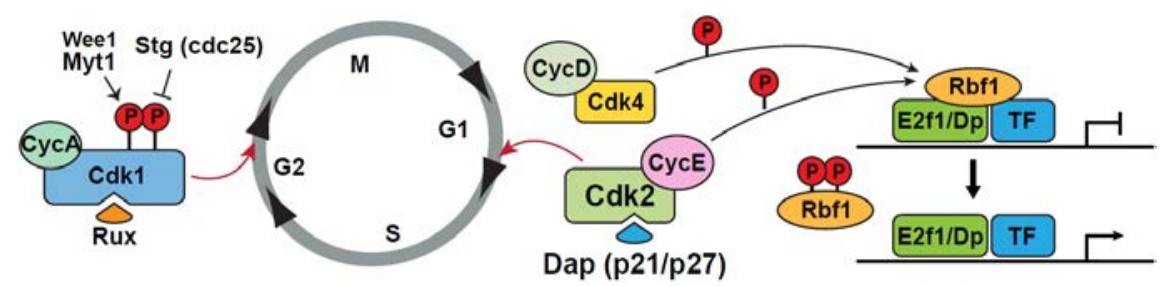

Figure 21: Schematic model for Drosophila Cell cycle regulation (Baumgardt et al., 2014).

\section{Apoptosis/Programmed Cell Death (PCD)}

Cells die during development and later in life through homeostasis, spontaneously or for physiological reasons. This coordinated cell removal is pivotal to morphogenesis during development and is termed programed cell death (PCD). PCD is genetically regulated and is evolutionarily conserved in all metazoan, and it ensures generation of proper cell numbers and removal of harmful or misspecified cells. The removal of larval tissues during insect metamorphosis, and the process of digit formation in vertebrates, are other typical examples 
of PCD-mediated developmental processes [129]. The genes involved in PCD were first discovered in C. elegans, and surprisingly, nematodes defective for PCD are still viable. However, flies and mice mutant for apoptosis genes are lethal and show severe CNS anomalies [153], showing the importance of PCD for neurodevelopment. As other studies demonstrate, the intrinsic developmental cues for each neural lineage determine if and when PCD should occur. In Drosophila CNS lineages, an NB can exit cell cycle by death, or first exit cell cycle and then die. Both modes are employed to trim the lineage and ensure the generation of the right numbers and types of cells $[122,130]$. Caspases are a conserved family of cysteine proteases which cleave a wide range of substrates. Caspase 3/7 are activated by both intrinsic (developmental, DNA damage) and extrinsic cues, and are the main executioners of PCD. The core pro-apoptotic genes in Drosophila are grim, reaper $(r p r)$, hid and sickle ( $s k l)$, all of which are antagonists of apoptosis inhibitors (IAPs). So when these antagonists are inactive, IAPs inhibit caspase9 (Drosophila Nedd2-like caspase; Dronc) and Apaf1 (apoptosis protease activating factor1) (Drosophila apaf1-related killer; Dark) by binding and polyubiquitylating them. In addition, Dronc and Dark negatively regulate each other to ensure that the apoptosome is not formed in living cells. Upon activation of the IAPantagonists, they inhibit IAPs by marking it for degradation for example via ubiquitylation, thereby allowing the formation of apoptosome and the activation of executioner caspases 3/7 (Fig. 22). Phagocytosis often follows apoptosis, and in the CNS glial cells are responsible for this process. The apoptotic cell is recognized by the phagocytic cell via its membrane proteins Draper and Simu $[154,155]$. In vertebrates, apoptosome is formed when mitochondrial cytochrome $\mathrm{C}$ is released into the cytoplasm, which is a Bcl-2-mediated process. This constitutes one major difference in the caspase-mediated apoptosis between vertebrates and Drosophila.

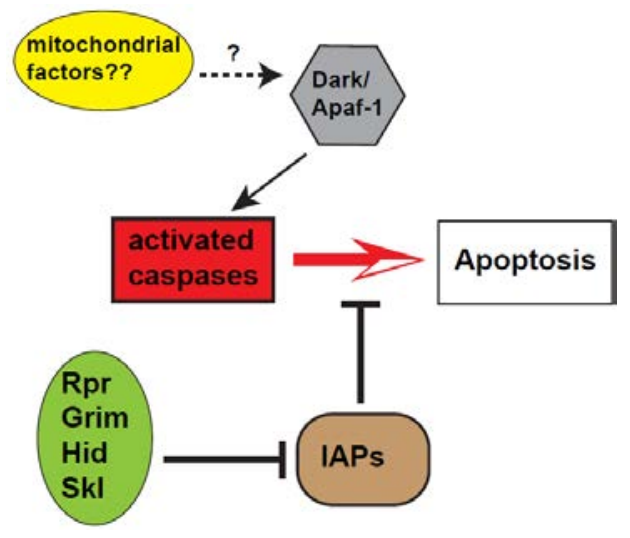

Figure 22: A simplified model for apoptosis in Drosophila (adapted from Kornbluth \& White, 2005). 


\section{CNS evolution; from the fruit fly to mammals}

A characteristic feature of all bilaterally symmetric animals (bilateria) is the existence of a centralized nervous system (CNS). Strikingly, upon formation of the CNS during evolution it immediately displayed an anterior expansion. This anterior expansion of the brain relative to the nerve cord is present in all bilateria, getting more pronounced in vertebrates to peak in mammals. The evolutionary origin of the modern bilaterian CNS is still fervently debated and studied, with experts adhering to two major schools of thought based on whether the ancestral urbilaterian had a centralized nervous system or a nerve net [156-162]. This debate is, principally, out of the scope of this book as none of my research projects addressed the evolution of the CNS directly. Nonetheless, it is briefly discussed here as it adds a very interesting perspective to several key topics of this dissertation, namely the antero-posterior differences in neurodevelopment and the comparison of the embryonic CNS in Drosophila and mouse. The existence of orthologous, D-V opposing morphogens such as Dpp/BMP vs chordin/sog in a both protostomes i.e., Drosophila, and deuterostomes i.e., vertebrates, lent support to the theory of a "urbilaterian with a CNS", since it implies that the CNS in protostomes and deuterostomes must have evolved from a common ancestor with a ventral nerve cord. This would have been followed by a D-V inversion either early in the deuterostome lineage or in the chordate lineage. On the other hand, functional and gene expression data from an enteropneust (acorn worm) which belongs to hemichordates; a sister phylum to Chordata and intermediate between protostomes and chordates, has been interpreted as evidence for the existence of an ancestral deuterostome with a nerve net and by extension for the "urbilaterian with a nerve net" theory. This theory implies that the centralized nervous systems in protostomes and deuterostomic chordates evolved independently as two separate events from nerve cords or ectodermal nerve nets of the ancestral urbilaterian (Fig. 23).
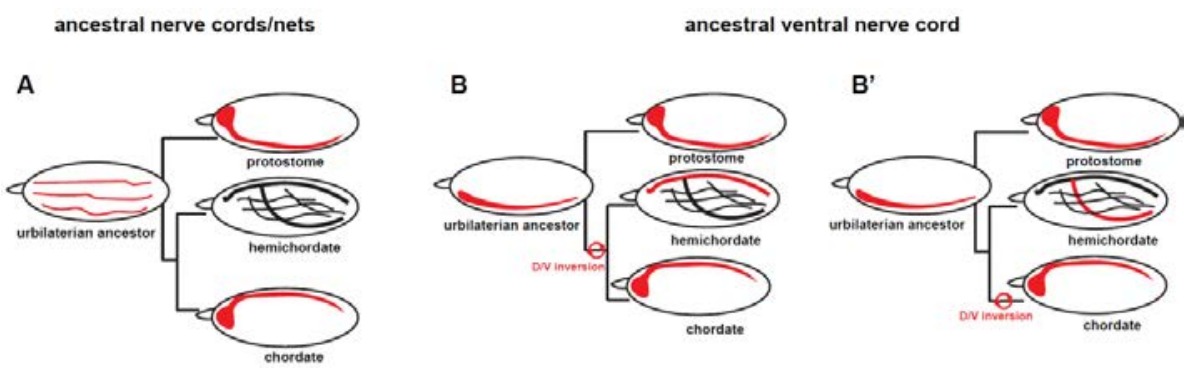
Figure 23: Different scenarios for the evolution of bilaterian CNSs. (A) the urbilaterian ancestor had multiple nerve cords or a nerve net in which case the CNS of protostomes and chordates evolved independently. (B) The urbilaterian had a centralized ventral nerve cord and the D/V inversion occurred in deuterostome lineage so hemichordate's dorsal nerve cord is homologous to protostome VNC and chordate CNS. (B') The inversion occurred in the chordate lineage so hemichordate's ventral nerve cord is homologous to chordates and protostome CNSs (adapted from Holland L Z. et al., 2013).

Irrespective of its origin and evolution, the differences between the brain and the nerve cord with regard to the anterior expansion of the nervous tissue in all extant bilaterally symmetric organisms could be logically attributed to four main developmental causes: 1) more progenitors anteriorly; 2) progenitors divide more anteriorly; 3 ) daughter cells divide more anteriorly; 4) there is less PCD anteriorly.

Regarding the first issue of more progenitors, the neural plate is indeed larger anteriorly in vertebrates and there are more NBs delaminating in the brain segments of the Drosophila embryo. Hence, this is a likely contributing factor to anterior CNS expansion, but begs the question of why there are such A-P differences in progenitor numbers in the first place? This question then leads us to the A-P differences in the neurogenic ectoderm (neuroectoderm or neuroepithelium) and how very early in development, the cross-talk between different maternal morphogens and signaling pathways set the stage in favor of anterior generation of more progenitors or how in vertebrates, the A-P differences in notochord/prechordal plate induction of the underlying ectoderm result in more elaborate anterior neural plate.

Regarding the $2^{\text {nd }}$ and $3^{\text {rd }}$ issues, that progenitors and daughters divide more anteriorly, while a number of studies have analyzed proliferation in the brain and nerve cord/spinal cord, in both Drosophila and vertebrates, prior to this thesis there were few if any comparative studies published. However, intriguingly, there are indications that the massive brain expansion in higher mammals and the transition from rodent-like lissencephalic cortex into primate-like gyrencephalic cortex may be, at least in part, driven by increase of daughter cell proliferation [163].

Similarly, regarding the $4^{\text {th }}$ issue, less PCD anteriorly, prior to this thesis no studies to date had addressed the impact of PCD on cell numbers in the entire CNS in Drosophila. Moreover, in mammals, the lack of genes that can abolish all PCD have made such studies impossible to date. 
Irrespective of the driving mechanisms of anterior expansion, many of which have been resolved in this thesis, the evolutionarily-conserved features of anterior CNS development and expansion are even more intriguing in light of the theories suggesting that the two parts of the CNS; brain and the nerve cord, might have existed separately in the common ancestor of bilateria and annelids as ANS (apical nervous system) and BNS (basal nervous system) and have merged together throughout evolution to form the modern CNS [159, 161, 164, 165]. 


\section{Methods}

\section{GAL4/UAS transgenic expression system}

This transgenic expression system was borrowed from the yeast Saccharomyces cerevisiae, in which GAL4 codes for a transcription factor which binds specific sites of its target genes. These sites are similar to enhancer elements in multicellular organisms and are called Upstream Activating Sequences (UAS). This system was adapted for spatial and temporal ectopic expression of desired genes in Drosophila and several other systems. By selecting a specific regulatory element to drive GAL4 expression (enhancer-promoter sequence; the driver), the spatial and temporal onset of GAL4 can be precisely controlled, so the ectopic expression is allowed to occur in a specific tissue or cell type at a particular time, all determined by the driver. When the two transgenic lines, one with the driver-GAL4 and the other with $U A S$-gene-of-interest are crossed together, the progeny with both constructs expresses the gene of interest in a spatio-temporal pattern dictated by the driver. The GAL4/UAS system can be used for misexpression of genes, rescue and cross-rescue experiments to determine the effect of a cDNA, or the genetic relevance of different factors in a biological process. It could also be used to express reporter constructs such as GFP/RFP or to knockdown certain genes of interest by misexpressing targeted RNAi against them [166].

\section{Transgenic mice}

To circumvent early embryonic lethality, it is desirable to use conditional alleles. The most commonly used set-up in the mouse system is the Cre-lox system, adapted from bacteriophage P1. In this system, the targeted gene (the whole gene or key exons) is flanked by loxP sites; short 34-bp DNA sequences. The insertion of loxP sites typically does not affect the function of the targeted gene. The loxP sites are recognized by the Cre recombinase, which creates a DNA loop, and either excises or inverts the looped segment, depending upon the orientation of the loxP sites (directed against each other = inversion; directed in the same direction = deletion). Cre is expressed from a transgenic construct, either a Cre knock-in into another gene or as a transgenic construct, and is usually referred to as a Cre deleter strain [167].

The CNS-specific knockout for Eed was generated by crossing a floxed allele of Eed with the loxP sites flanking exons 3 to 6 of the Eed locus [168] to Sox1-Cre, which is expressed from 
E8.5 onwards in the entire CNS (denoted Eed-cKO). Embryos were identified by PCR genotyping using specific primers for Cre and floxed Eed. Limb buds of embryos were harvested and DNA was extracted (NaOH DNA extraction) followed by PCR and gel electrophoresis.

\section{Immunohistochemistry (IHC)}

IHC is the use of monoclonal or polyclonal antibodies, specific to a protein which we want to detect, and visualize for quantitative or qualitative analyses. To preserve the cell morphology and tissue integrity $4 \%$ paraformaldehyde (PFA) is used. PFA fixes the tissue mainly by cross-linking proteins. Then the cells should be permeabilized with a detergent such as Triton-X to enhance antibody diffusion into cells. After that the blocking agent e.g., horse serum is added to minimize non-specific binding of antibodies and reduce the background staining. Primary antibodies are then applied, which have specific non-covalent affinity to epitopes of the studied proteins. Then secondary antibodies, which have affinity for the species-specific domain of the primary antibodies, are added. Secondary antibodies are conjugated with fluorophores that are excitable at certain wavelengths, and upon excitation emit light at certain (lower) wavelengths, which is detected by the microscope. Alternatively, secondary antibodies can be conjugated to an enzyme, such as HRP (horseradish peroxidase), AP (alkaline phosphatase) or $\beta$-gal (beta-galactosidase). Upon exposure to the appropriate substrate, the enzymatic reaction produces a product with a detectable color.

\section{Confocal scanning and image analysis}

Please see papers I, II and III for information.

\section{Electroporation in chicken embryos}

Please see paper III for information. 


\section{Statistics}

The statistical approach or practice is determined by the types of samples that are being compared and the nature of variables being considered in the study. It should be considered if they are numerical (quantitative) or categorical (qualitative), or if the groups or data sets are paired or unpaired i.e., if the values in one group could be affected by values in another or not, respectively. Since data sets in our studies are all considered unpaired, here I focus on this type of data. For quantitative variables, we first have to determine if the population is normally distributed, which means if they follow the Gaussian curve, in order to decide between parametric or non-parametric tests. If the distribution is normal, parametric tests, which requires the assumption of the sample being from a normally distributed population, should be used, such as unpaired $t$ test for two groups and ANOVA for multiple groups. If the distribution is not normal, non-parametric tests are applicable, such as Mann-Whitney $U$ test for two groups and Kruskal-Wallis test for multiple groups. The test of normality which I have used in my statistical analyses is either Kolmogorov-Smirnov or Shapiro-Wilk, depending on the sample size. These two analyses test the null hypothesis that the samples are normally distributed and depending on the returned values the hypothesis is either accepted or rejected.

In comparison of multiple groups, when either ANOVA or Kruskal-Wallis test is statistically significant, a post-hoc test is required to see which groups are meaningfully different. For normally distributed data sets, the choice of the appropriate post hoc test depends on the assumption of equal variance or the assumption of homogeneity of variance i.e., all groups have equal variances. To determine this, Levene's test is used. If this test yields a significant $p$ value, the equal variance is not assumed and the common post-hoc tests used in our study were Tamhane's T2 or Dunnett's T3 tests, based on degrees of freedom and sample size. If Levene's test returns a non-significant $p$ value, the homogeneity of variance is assumed and then Bonferroni test is used. For non-parametric comparison of multiple groups, pair-wise application of Mann-Whitney $U$ test or Dunn's test are commonly used. For categorical (qualitative) dada sets, we used Chi-square $\left(\chi^{2}\right)$ test or Fisher's exact test depending on the sample size. 


\section{Results \& discussion}

\section{Paper I: Global Programmed Switch in Neural Daughter Cell Proliferation Mode Triggered by a Temporal Gene Cascade.}

\section{Background and Aims}

The Drosophila CNS consists of brain and the ventral nerve cord (VNC), generated by some 1,200 NBs formed during embryogenesis [97, 169-172]. Each NB delaminates from the neuroectoderm via lateral inhibition [114], and as an effect of early patterning mechanisms (outlined above) has a unique competence and identity, therefore giving rise to a unique lineage by repetitive asymmetric divisions. As outlined above, NB progression is temporally controlled by a series of transcription factors and co-factors (temporal factors), and hence every daughter cell is born in a unique temporal window. As NBs divide they self-renew and also generate a daughter cell. The daughter cell was historically believed to always divide once, to generate two neurons or glia. However, three papers in 2008 pointed to the existence of a different division mode [119-121], whereby the NB generates daughter cells that can divide multiple times. This was denoted Type II, and at the same time the historically wellknown division mode was referred to as Type I. Studies from Chris Doe's and Stefan Thor's labs $[118,127]$ had identified a third division mode, whereby NBs budded off daughter that directly differentiated. Type II division mode was only described in the embryonic and larval brain, while the extent and genetic control of the other two division modes was not known. The aims of the first study in my thesis were to:

-Characterize the extent and nature of alternate division modes in the embryonic VNC.

-Determine whether or not NBs switch between such different division modes.

-Identify genetic factors and mechanisms underpinning the different daughter cell division modes.

I aimed to address these issues at high resolution, using discrete lineage markers as well as on a global scale, to figure out whether such mechanisms exist and if yes whether they are extendable into a general regulatory strategy. 


\section{Main Findings}

All three lineages studied in this paper (NB5-6T, NB3-3A and NB7-3A) show a distinct, temporally controlled daughter cell proliferation switch. The direct division mode was coined Type 0 in this study, and hence we found that these three NBs undergo a programmed Type I$>0$ switch. Global analysis of NB and daughter cell proliferation at fixed intervals during neurogenesis from stage 10 until stage 17, using antibodies against well-defined markers such as Pros, Dpn and PH3 to help us discriminate between mitotic NBs and mitotic daughter cells as well as cell cycle length considerations for NBs and daughter cells demonstrated that the Type I- $>0$ switch occurs in the entire VNC for the majority of lineages. It is therefore a general, programmed switch to control cell type and number. Using NB5-6T and the thoracic $\mathrm{VNC}$ as a readout for Ap neuron numbers (Eya/FMRFa/Nplp1 positive cells) or mitotic index respectively, we identified $E 2 f, C y c E$ (G1 regulators), dap (G1 inhibitor), as well as $C y c A$, $C d k 1, C y c B, C y c B 3$ and $s t g$ (G2 regulators) as important effectors of proliferation and the division mode switch. In particular, we demonstrated a critical role for the onset of Dap expression as key for the Type I->0 switch, for all the three lineages studied, as well as globally in the thoracic VNC. The robust Dap expression in NBs is detected before they enter Type 0 window, but is absent in Type I window which agrees with the data showing absence of Dap in early VNC [173, 174]. Type I-born daughters also express average levels of Dap before division and it is maintained in their progeny. Type 0 daughter cells show robust Dap expression. Interestingly, the ratio of Dap+/- NBs over time agrees with the inferred Type 0 divisions in the VNC. Misexpression experiments, using the early, pan-neural driver pros$G A L 4$ [141] showed that $E 2 f-D p$ or $C y c E-C d k 2$ could increase NB division, while only $C y c E$ $C d k 2$ or the quadruple misexpressions ( $C y c E-C d k 2-E 2 f-D p)$ could extend daughter cell division and override Type I- $>0$ switch. Misexpression of dap only attenuated daughter cell proliferation, underscoring its selective role in the Type I->0 switch. Mutant analysis in NB5$6 \mathrm{~T}$ and globally in thoracic VNC revealed the role of the temporal factor cas and the Hox gene Antp in control of both the Type I- $>0$ switch and NB cell cycle exit, as evident by aberrant and supernumerary proliferation of both NBs and daughter cells. The late temporal factor grh mainly controls NB cell cycle exit in NB5-6T lineage and globally, but also had a minor global effect in the Type I->0 switch. Measuring candidate cell cycle protein levels in Antp, cas and grh mutants revealed increased E2f levels in all three mutants, increased CycE levels in cas and grh mutants and decreased Dap levels in Antp and cas mutants. Misexpression of Antp-cas resulted in proliferation reduction of both NBs and daughter cells 
globally and daughter cells in NB5-6T, which in indicative of a premature Type I- $>0$ switch and NB exit. The premature switch, induced by Antp-cas misexpression was accompanied by the premature onset of Dap expression in NB5-6T and its daughter cells. The cross-rescue of cas mutants with regard to loss of Type I- $>0$ switch and NB exit with dap re-expression demonstrate the role of dap in cas mutant effects and genetically places dap downstream of cas (Fig. 24).
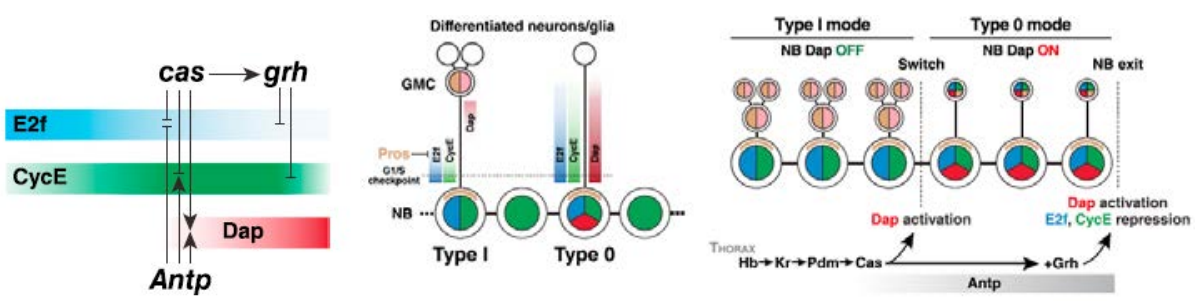

Figure 24: (Left) Model of E2f, CycE and Dap regulation by Antp, cas and grh. (Middle) Mechanisms of Type I and 0 proliferation modes. (Right) Mechanisms behind the Type I $>0$ switch and NB exit in thoracic VNC (Baumgardt et al., 2014).

\section{Paper II: Anterior-Posterior Gradient in Neural Stem and Daughter Cell Proliferation Governed by Spatial and Temporal Hox Control.}

\section{Background and Aim}

A common feature of the CNS in all vertebrates and many invertebrates is that the CNS is larger anteriorly, which is manifested in the "wedge-like" shape of the CNS. As outlined in the Evo-Devo section above, this noticeable appearance could be logically attributed to four major issues: A-P differences in progenitor numbers, progenitor proliferation extent, modes of daughter cells proliferation, and PCD.

Regarding the Drosophila VNC, systematic mapping of cell numbers in each segment of the VNC had not previously been done, and hence cell number differences were not known. Regarding progenitors, it was known that a repetitive array of some 30 NBs delaminate in most segments of the embryonic VNC (T1-T3-A1-A7), with the exception of the posteriormost segments (A8-A10), in which fewer NBs delaminate [175, 176]. Having identified the Type I- $>0$ switch, and precise NB proliferation stop, as well as some of the genetic 
mechanisms controlling this, we wanted to address how these events are modified along the A-P axis of the VNC. This study had several goals:

-Map cell numbers in all VNC segments.

-Map NB and daughter proliferation in all VNC segments.

-Determine the input of PCD on proliferation and cell numbers

-Identify genetic cues that may act to modify these issues along the A-P axis

\section{Main Findings}

Our global as well as lineages analyses (NB5-6, NB3-5) demonstrated an A-P gradient in cell numbers, with anterior segments having more cells. We also demonstrated the occurrence of Type I- $>0$ switch in daughter cell proliferation mode which corresponds to lineage size and cell numbers for both lineages studied, with NB3-5 showing a generally delayed switch compared to NB5-6 resulting in an extended Type I window. The A-P gradient of proliferation for both NBs and daughter cells, observed over several developmental stages, could be interpreted as an earlier Type I- $>0$ switch and NB cell cycle exit for posterior segments. Proliferation analysis of ED225 mutants (a mutant that abolishes PCD) revealed minor effects on NBs due to a subset of lineages in which NB exit is mediated by PCD, but no effects on daughter cells. The A-P gradient of cell numbers was further maintained in ED225 mutants. However, PCD proved to be an important player in controlling cell numbers in the entire VNC, as all segments showed increases cell numbers in PCD mutant background, with a more prominent increase in A8-A10. This is attributed to PCD role in NB and post-mitotic cell removal.

One suitable candidate gene family for these A-P differences are the Hox homeotic genes, which are expressed in defined domains in the VNC along the A-P axis. We did not observe any BX-C Hox proteins expression early in NBs (st 11), while they started to be robustly expressed later in NBs around stage 13. This temporally coincides with the Type I- $>0$ switch globally. Proliferation analysis of abdominal segments in $U b x$ and $a b d-A$ mutants showed increased division only for daughter cells in A1 and A5 respectively while $A b d-B$ mutant showed increased NB proliferation in A9-A10, and for daughter cells in A8-A10. These findings point to $A b d-B$ having a role in the switch and the NB exit, but these effects are not 
PCD-mediated as we found no increase in proliferation in PCD mutants in A9-A10.

Proliferation analysis in double $a b d-A, A b d-B$ and triple $B X-C$ mutants did not show additive effects, presumably due to posterior prevalence effect. Misexpression of BX-C genes resulted in premature switch and, albeit to a lesser degree, NB exit, and these effects are not PCDmediated. In comparison to single BX-C gene misexpression, the triple misexpression did not result in additive effects. We demonstrated that the proliferative effects of the BX-C Hox genes is mediated mostly via control of the key cell cycle genes and their balanced expression. Measurement of $\mathrm{CycE}$, E2f, Stg and Dap protein levels in mitotic and non-mitotic $\mathrm{NBs}$, in single mutant and misexpression of BX-C genes, revealed their involvement in control of at least one these four cell cycle factors. This study revealed that there is a gradient of cell numbers along the VNC. This is driven by a 1) gradient of NB numbers, at least with regard to A8-A10,2) a gradient of NB proliferation, 3) a gradient of the Type I->0 switch. It is however, not driven by PCD. We also found that Hox genes, with their region-specific, overlapping expression domains along the A-P axis and late temporal onset in NBs during neurogenesis, are important contributors to the A-P differences of the Type I- $>0$ switch, NB exit and lineage size, which all finally culminate in the formation of a wedge-like VNC (Fig. 25).

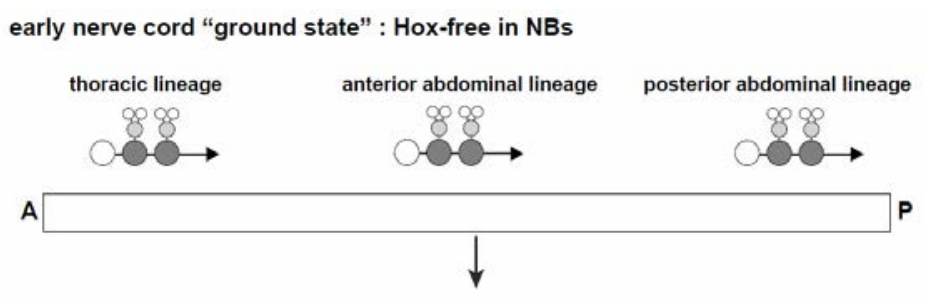

late nerve cord: Hox gradients in NBs $--\mid$ cell cycle

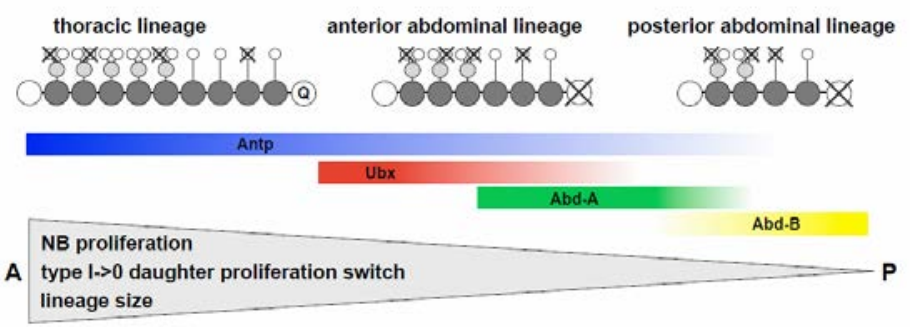

Figure 25: How the spatio-temporal Hox gene expression along the A-P axis in the developing $\mathrm{VNC}$, determine the gradients of Type I $>0$ switch, NB exit and thereby the lineage size. PCD is important for the proper neurodevelopment but these A-P differences are not PCD-mediated (Monedero et al., 2017). 


\section{Paper III: Evolutionarily Conserved Anterior Expansion of the Central Nervous System Promoted by a Common PcG-Hox Program.}

\section{Background and Aim}

The existence of a centralized nervous system (CNS) is a characteristic feature of all bilaterally-symmetric organisms. Irrespective of its evolutionary origin and trajectory, a common yet unquestioned feature of the CNS is its anterior expansion. This feature is evolutionarily conserved, from annelids and arthropods to vertebrates and culminates in mammals. Following the same logic as for the VNC, the anterior expansion of the CNS could be attributed to four major features of the developing embryo and their differences along the A-P axis: the number of progenitors, the extent of progenitor proliferation, the extent and mode of daughter cell proliferation and PCD. The aim of this study was to build upon our results in Paper I and II, and address the existence and extend to which each of these four features contribute to the anterior expansion of the CNS in Drosophila and mouse embryos. In Drosophila embryos we focused on representative segments along the A-P axis; the B1-B2 brain segments as the most anterior part, the T2-T3 segments and the A8-A10 as the most posterior parts. In mouse embryos the focus was on the telencephalon and the spinal cord at the lumbo-sacral axial level.

\section{Main Findings}

In the Drosophila CNS we found a gradient of cell numbers and average lineage sizes along the A-P axis, with the brain NBs generating lineages that are, on average, almost twice as large as the ones in the thorax, and with thoracic lineages being, on average, twice as large as the abdominal ones (Fig. 26). These A-P differences were even more pronounced in PCD mutants, showing the PCD-mediated removal of considerable numbers of progenitors, daughter cells and post-mitotic cells in the brain. Surprisingly, this study systematically demonstrated that reduced PCD in the brain is not a driving factor for anterior expansion of CNS.

Interestingly, we also found extended and elevated NB and daughter cell proliferations in the brain compared to the VNC and no evidence for a general Type I->0 switch in the brain. EdU pulse-labeling experiments further demonstrated that brain daughter cells cycle faster than the ones in the VNC. 

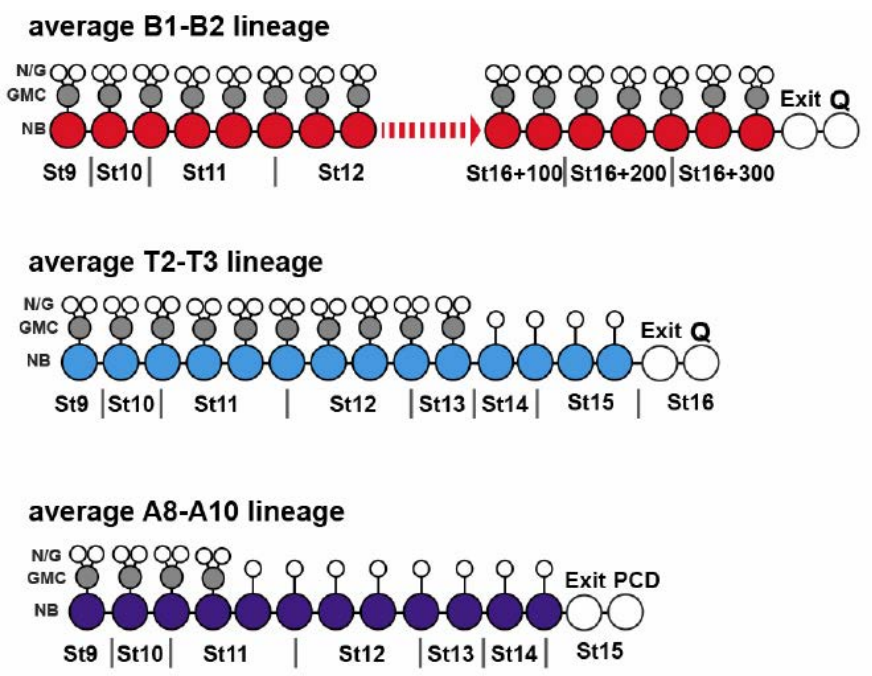

Figure 26: Schematic lineage trees based on the calculated average lineage sizes in different segments of the Drosophila CNS. NB: neuroblast; GMC: ganglion mother cell; N/G: neuron/glia; Q: quiescence; PCD: programmed cell death (Yaghmaeian et al., 2018).

The protein levels of the cell cycle drivers CycE, E2f and Stg were also higher in the brain NBs than the VNC segments, while Dap levels were not different.

The brain in most, if not all, bilateria is void of Hox gene expression. Given our findings in Paper II of the involvement of Hox genes in controlling NB proliferation and the Type I->0 switch, we misexpressed them in the brain. Indeed, we found that triple misexpression of the $B X-C$ genes reduced NB and daughter proliferation in the brain. These effects were maintained in PCD mutants, even though the mere misexpression of the BX-C genes reduced the number of NBs in B1-B2. This demonstrates the direct effect of the studied Hox genes in proliferation control of NBs and daughter cells as well as their indirect effect via PCDmediated removal of NBs and possibly daughter cells. BX-C misexpression also lowered the protein levels of CycE, Stg and Dap while Ef2 was not affected. We found that BX-C misexpression also reduced the total number of cells in B1-B2 and the average brain lineage size, irrespective of PCD as the experiments were done in a PCD mutant background.

The absence of Hox gene expression in the brain, the role of Hox genes in the VNC, and the effects of Hox gene misexpression, demonstrates that anterior CNS expansion is, at least in 
part, controlled by preventing Hox gene expression anteriorly. What controls this? A complex known to control Hox gene expression is the Polycomb group (PcG) complex. PRC1 and PRC2 carry out post-translational modifications of key residues on histone tails. PRC1 ubiquitylates $\mathrm{H} 2 \mathrm{~A}$ and PRC2 methylates $\mathrm{H} 3 \mathrm{~K} 27$ which results in the repression of their target genes including Hox genes. Both PcG and Hox gene groups are highly conserved. PcG is already found in the budding yeast $[177,178]$, while Hox genes presumably showed up in the cnidaria-bilateria common ancestor $[84,179]$.

To address the role of PcG in controlling Hox gene expression, and participate in anterior expansion, we addressed extra sex comb (esc) maternal-zygotic mutants, a core component of PRC2. We found that H3K27me3 marks were lost form the entire CNS and that Antp, Ubx, abd-A and Abd-B were expressed in the brain. In these mutants, proliferation of NBs and daughter cells in the brain and posterior VNC were not affected early in development (stage 11) when Hox genes are not yet robustly expressed in the NBs. However, at stage 13, NB and daughter cell proliferation were reduced in the brain, while the VNC was not affected. Total cell numbers and average lineage sizes were also reduced in the brain and not in A8-A10. These effects were maintained in PCD mutants. CycE, Stg, and E2f protein levels were reduced in esc mutant in brain NBs while Dap was upregulated. EdU pulse-labeling also revealed slower daughter cells in esc mutant only in the brain, while A8-A10 was not affected.

To address if these A-P differences and the role of PcG and Hox genes is evolutionary conserved, we analyzed mouse embryos. Proliferation analysis in the mouse embryo from E10.5 until E18.5 demonstrated more mitotic activity in telencephalon (Tel) compared to spinal cord (SC) from E13.5 onwards. EdU pulse-labeling at two different stages resulted in identification of faster cycling cells in Tel compared with SC. Due to the lack of distinct markers to discriminate progenitors from daughter cells across different axial levels in mouse embryo, we used the well-established "distance to lumen" as a criterion for mitotic progenitors versus daughter cells, with cells dividing further than $20 \mu \mathrm{m}$ form the lumen categorized as daughter cells since neural progenitors in mammals are known to divide very close to lumen. This revealed an increase in daughter proliferation in Tel compared to SC from E13.5 onwards. Transcriptome (RNA-seq) analysis of the forebrain versus the entire SC at E13.5 showed upregulation for several cell cycle genes such as $C c n e 1 / 2(C y c E)$, Cdc25a/b/c (stg), Cdkn1a/b (dap), E2f1/2/3 (Ef21), Ccna2 (CycA) and Ccnd2 (CycD). We generated a CNS-specific knockout for Eed, a core PRC2 component and esc orthologue, via 
the cross of a floxed allele of Eed to Sox1-Cre, which is expressed from E8.5 onwards in the entire CNS (denoted Eed-cKO). Eed-cKO mice displayed loss of $\mathrm{H} 3 \mathrm{~K} 27 \mathrm{me} 3$ from the entire CNS from E11.5 onward, and were microcephalic, most obvious at E15.5 and E18.5.

Proliferation in Tel is reduced in Eed-cKO embryos at E15.5 and E18.5 compared with control, while SC was unaffected at all examined stages. The ratio of progenitors (Sox $2+)$ to all cells was also reduced in Tel but not in SC. Transcriptome (RNA-seq) analysis of Eed$c K O$ versus control forebrains at E15.5 showed extensive upregulation of all Hox genes and posterior-specific genes. In contrast, brain-specific and core pro-proliferative cell cycle genes were downregulated, while cell cycle inhibitor genes such as Cdkn1a and Cdkn1c were upregulated. Staining for p27 (Drosophila Dap), cleaved caspase 3 and Sox2, together with EdU pulse-labeling in control and Eed-cKO embryos demonstrated that in the knockout Tel, the developmental program is truncated, as evident by the reduced Sox + ratio and Edu incorporation, fewer PH3+ cells, increased p27 expression and premature occurrence of PCD while none of these markers were affected in the SC.

Together, data from mouse and Drosophila indicates a gradient of proliferation of both progenitors and daughter cells in the developing CNS, with elevated and extended proliferation in the brain. Genetic and transcriptome studies in these two systems reveal a conserved role of PcG-Hox program to promote anterior expansion. In this scenario, the repressive function of $\mathrm{PcG}$ to shut down Hox gene expression anteriorly is pivotal in keeping the brain more proliferative either directly by activating brain-specific genes or cell cycle genes or indirectly by keeping Hox genes repressed (Fig. 27).
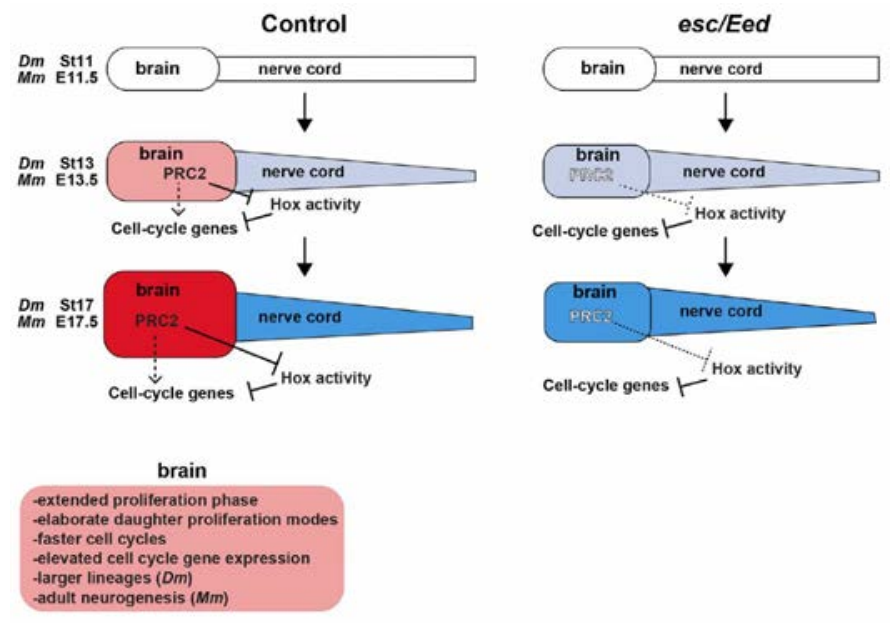

Figure 27: PcG-Hox interactions directly and indirectly promotes anterior CNS expansion. PcG-mediated Hox repression becomes more important for anterior expansion as neurogenesis progresses (Yaghmaeian et al., 2018). 


\section{Concluding Remarks}

The three research projects presented in this dissertation have uncovered intricate genetic regulatory networks that underlie embryonic CNS development, in particular with regard to the proliferation control. Many features of development including neurogenesis are determined very early in developmental time via the interactions of maternally-loaded morphogens and early zygotically transcribed genes to set the stage for later developmental programs. However, thus far, little is known about how neurogenesis is controlled once the neurogenic ectoderm is established i.e., after the delamination of NBs from neuroectoderm or after neural plate formation. Valuable studies have clarified the molecular machinery of asymmetric cell division which is the cornerstone of neurogenesis or the temporality of neural progression and its tight connection to fate determination. Despite all these advances, much has been left to explore with regard to the control of proliferation extent and mode, in particular, of daughter cells. Another very interesting question was how these developmental regulations are adjusted along the A-P axis.

In paper I, we discovered that the Type I- $>0$ daughter cell proliferation mode switch is a global phenomenon in Drosophila. We also found that the key factor in regulating the Type I$>0$ switch is the dacapo KIP-family inhibitor. We found that a temporal program involving cas and Antp controls dacapo. This control confers spatio-temporality to the switch which makes it adjustable for different parts of the CNS along the A-P axis. This aspect was highlighted in paper II in which the universality of the switch and NB exit is demonstrated in an axial context. We also linked the late onset of Hox expression in NBs to the switch.

One common finding in all my studies is that proliferation control, irrespective of its axial position in the CNS, is always mediated via key cell cycle factors. My studies, per se, do not address whether this mediation is direct or not. Other studies have demonstrated the direct link between some of these regulators such the HD transcription factor prospero and cell cycle genes such as $C y c E, E 2 f$ and $s t g$ [180]. Irrespective of that, the proliferation control by Hox genes, PcG genes or temporal factors is evidently always mediated via cell cycle factors. Should the former be the modulating "hands", the latter are the "knobs" of the proliferation machinery.

One important finding of my work was to show that the A-P gradient of proliferation and cell number is independent of the PCD. Despite the pivotal role of PCD in embryogenesis including neurogenesis, the A-P differences in cell number, average lineage size and 
proliferation are not mainly, if at all, regulated by PCD. In paper III, we demonstrated that PCD is even more prevalent in the brain than the VNC of Drosophila.

In paper III, a very interesting evolutionary perspective was given to the A-P specific control of proliferation. Here we strived to address the same questions not only in the brain but also in another model system, the mouse. The distinction is twofold; the brain in almost all bilateria is Hox free, and the gradient of cell number and proliferation is much steeper in the brain, as if it has come from a different "world". The Hox-free brain is attributed to the PcGmediated repression of Hox genes in the brain and our studies in both the fly and the mouse point towards an evolutionarily and developmentally important interaction between PcG and Hox genes to promote and maintain the brain expansion throughout development (Fig. 28). So, if PcG components are globally expressed in the entire CNS and are functional, as evident by H3K27me3 marks in the control CNS, why do they repress Hox genes only in the brain? This very interesting, yet fundamental question takes us back to what has been discussed briefly in the introduction. The function of PcG, like other chromatin remodelers is context dependent and combinatorial. PRC2 which is responsible for trimethylation of H3K27, like any other competent writer, should be able to read first! PcG's main role is transcriptional repression indeed, but the choice of the targets is a different matter. It could be that in more posterior parts of the CNS Hox regulatory loci are not repressed due to a different permissive chromatin landscape. Other pioneer transcription factors could override PcG-mediated repression and trigger transcription. The combinatorial assembly of PcG complexes could be different such that Hox loci are kept transcriptionally active. Besides, PRC2 recruitment could be affected by different degrees of ubiquitination. Last but not least, chromatin architecture, in many cases, is determined much earlier in development, way before the onset of Hox genes and this chromatin landscape could also be adjustable and differentially decorated at different axial levels of the CNS by the functions of early developmental factors such as patterning morphogens and signaling pathways.

Finally, the discovery of similar daughter cell proliferation modes in a wide span of species from Drosophila to mammals becomes even more intriguing in light of the theories suggesting that alternate daughter cell proliferation modes could account for the evolution of the brain expansion $[163,181,182]$. 


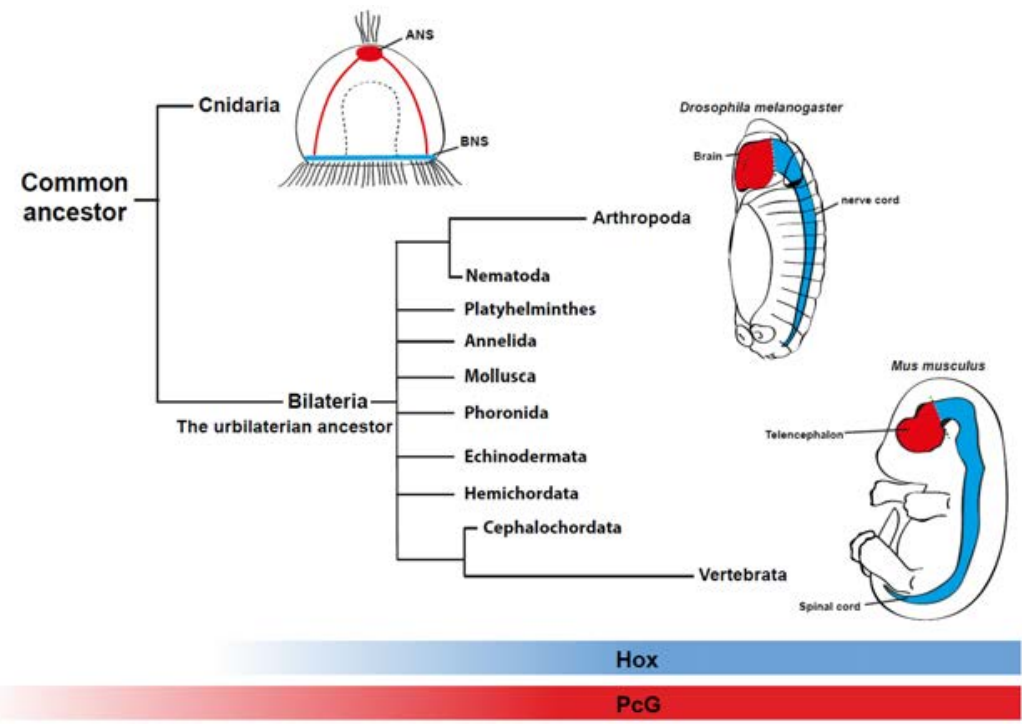

Figure 28: Simplified phylogenetic tree depicting CNS evolution from the apical and basal nervous systems (ANS and BNS) in the Cnidarian-bilaterian ancestor and with regard to PcGHox program. 


\section{Acknowledgements}

I would like to express my most sincere gratitude to all the people who directly or otherwise have helped me with my doctoral studies and the preparation of this dissertation.

My very special thanks to my supervisor Stefan Thor. You have provided me with incredible intellectual support and professional training. You've been motivating and approachable. The breadth and depth of your knowledge has been both astounding and inspiring to me. It's been a great opportunity to work in your lab, tough but fun!

My co-supervisor Jan-Ingvar Jönsson for valuable support, encouragement and interesting discussions. Thank you for reviving my confidence when I was down and faltering.

My warm and heartfelt thanks to all my colleagues and friends in Thor Lab; past and present.

To Magnus, my mentor and friend for teaching me most of what I know about fly pushing, dissection, IHC, confocal microscopy etc. For all the good and fun talks we had. To Annika, Carolin and Helen for their amazing support, technical or otherwise. You guys make a huge difference in the lab and for that I'm much obliged! To Nacho, for being an incredible colleague and friend, who's always willing to help so generously. I've learned a lot working with you and honestly, I couldn't have asked for a better co-author on the last two papers! Muchas gracias!

To Johannes, Jonathan, for being amazing friends and colleagues. It's been a pleasure to work with you guys! I've learned so much from you and truly cherish your friendship. To Shahrzad, for her unwavering support and all the joy and energy she brings to the lab, including the fly room disco! To Susanne for all her hard, meticulous work on the last paper and the invaluable support and understanding when I was really stressed out! To Jesus, Josefin, Caroline and Erika for your incredible attitude, positive energy and your generous support and help. To Badrul and Farjana, a very nice and hardworking couple whom I'm happy to know. To all the former members of the lab; Daniel, Ryan, Anna, Hugo for their useful advice and great sense of humor.

To my dear friends in Sweden with whom I share so many wonderful memories, Johan for all the fun games and activities, the trips we took, especially the memorable one to Copenhagen which was hosted by my other good friend Magali. To Eli for your good heart and cosmic energy. You've introduced me and Razi to your kind and hospitable family in Italy, on an unforgettable trip. To my Iranian friends Shadi and Farshid, a lovely couple whom I'm lucky to know. To Sarah for all the fun talks we had and the amazing parties she throws with her lovely family. To all the other people on Floor 13, for creating an amazing environment and to all my other friends whose names are not mentioned in here! 
Last but not least, I'd be remiss not to express my gratitude to my dear family. To my mom and dad and my brother Behrooz whose support and encouragement has helped me throughout my life. To my kind and lovely sister-in-law, Artemis and her amazing family for showing interest in my work and asking after me. To my loving wife Raziyeh, to whom I am deeply indebted. None of this would be possible without your support and encouragement sweetheart! 


\section{REFERENCES}

1. Mueller, W.A., M. Hassel, and M. Grealy, Development and reproduction in humans and animal model species. 2015.

2. Slack, J.M.W., Conrad Hal Waddington: the last Renaissance biologist? Nature Reviews Genetics, 2002. 3: p. 889.

3. Wolpert, L., Positional information and the spatial pattern of cellular differentiation. Journal of Theoretical Biology, 1969. 25(1): p. 1-47.

4. Tuazon, F.B. and M.C. Mullins, Temporally coordinated signals progressively pattern the anteroposterior and dorsoventral body axes. Seminars in Cell \& Developmental Biology, 2015. 42: p. 118-133.

5. Hartenstein, V., Atlas of Drosophila development. 1993, Plainview, N.Y.: Cold Spring Harbor Laboratory Press. v, $57 \mathrm{p}$.

6. Nusslein-Volhard, C., Determination of the embryonic axes of Drosophila. Dev Suppl, 1991. 1: p. 1-10.

7. Sanson, B., Generating patterns from fields of cells. Examples from Drosophila segmentation. EMBO Rep, 2001. 2(12): p. 1083-8.

8. Lewis Wolpert, C.T., and Alfonso Martinez Arias, Principles of Development. 5 ed. 2015: Oxford University Press. 720.

9. Ramos, C. and B. Robert, msh/Msx gene family in neural development. Trends Genet, 2005. 21(11): p. 624-32.

10. Hong, J.W., et al., How the Dorsal gradient works: insights from postgenome technologies. Proc Natl Acad Sci U S A, 2008. 105(51): p. 20072-6.

11. von Ohlen, T. and C.Q. Doe, Convergence of dorsal, dpp, and egfr signaling pathways subdivides the drosophila neuroectoderm into three dorsal-ventral columns. Dev Biol, 2000. 224(2): p. 362-72.

12. Logan, C.Y. and R. Nusse, The Wnt signaling pathway in development and disease. Annu Rev Cell Dev Biol, 2004. 20: p. 781-810.

13. Clevers, H., Wnt/beta-catenin signaling in development and disease. Cell, 2006. 127(3): p. 469-80.

14. Yamaguchi, T.P., Heads or tails: Wnts and anterior-posterior patterning. Current Biology, 2001. 11(17): p. R713-R724.

15. Perrimon, N., C. Pitsouli, and B.Z. Shilo, Signaling mechanisms controlling cell fate and embryonic patterning. Cold Spring Harb Perspect Biol, 2012. 4(8): p. a005975.

16. Dorey, K. and E. Amaya, FGF signalling: diverse roles during early vertebrate embryogenesis. Development, 2010. 137(22): p. 3731-42.

17. Diez del Corral, R. and K.G. Storey, Opposing FGF and retinoid pathways: a signalling switch that controls differentiation and patterning onset in the extending vertebrate body axis. Bioessays, 2004. 26(8): p. 857-69.

18. Mason, J.M., et al., Sprouty proteins: multifaceted negative-feedback regulators of receptor tyrosine kinase signaling. Trends Cell Biol, 2006. 16(1): p. 45-54.

19. Shen, M.M., Nodal signaling: developmental roles and regulation. Development, 2007. 134(6): p. 1023-34.

20. Kumar, S. and G. Duester, SnapShot: Retinoic Acid Signaling. Cell, 2011. 147(6): p. 14221422.e1.

21. Duester, G., Retinoic Acid Synthesis and Signaling during Early Organogenesis. Cell, 2008. 134(6): p. 921-931.

22. Cunningham, T.J. and G. Duester, Mechanisms of retinoic acid signalling and its roles in organ and limb development. Nat Rev Mol Cell Biol, 2015. 16(2): p. 110-23. 
23. Shi, Y. and J. Massague, Mechanisms of TGF-beta signaling from cell membrane to the nucleus. Cell, 2003. 113(6): p. 685-700.

24. Budi, E.H., D. Duan, and R. Derynck, Transforming Growth Factor-beta Receptors and Smads: Regulatory Complexity and Functional Versatility. Trends Cell Biol, 2017. 27(9): p. 658-672.

25. Bier, E. and E.M. De Robertis, EMBRYO DEVELOPMENT. BMP gradients: A paradigm for morphogen-mediated developmental patterning. Science, 2015. 348(6242): p. aaa5838.

26. Perino, M. and G.J. Veenstra, Chromatin Control of Developmental Dynamics and Plasticity. Dev Cell, 2016. 38(6): p. 610-20.

27. Pombo, A. and N. Dillon, Three-dimensional genome architecture: players and mechanisms. Nat Rev Mol Cell Biol, 2015. 16(4): p. 245-57.

28. Tolhuis, B., et al., Looping and Interaction between Hypersensitive Sites in the Active B-globin Locus. Molecular Cell, 2002. 10(6): p. 1453-1465.

29. Lupiáñez, Darío G., et al., Disruptions of Topological Chromatin Domains Cause Pathogenic Rewiring of Gene-Enhancer Interactions. Cell, 2015. 161(5): p. 1012-1025.

30. Paranjpe, S.S. and G.J. Veenstra, Establishing pluripotency in early development. Biochim Biophys Acta, 2015. 1849(6): p. 626-36.

31. Lin, C.-J., et al., Hira-Mediated H3.3 Incorporation Is Required for DNA Replication and Ribosomal RNA Transcription in the Mouse Zygote. Developmental Cell, 2014. 30(3): p. 268279.

32. Aoshima, K., et al., Paternal H3K4 methylation is required for minor zygotic gene activation and early mouse embryonic development. EMBO reports, 2015. 16(7): p. 803-812.

33. Lu, F., et al., Establishing Chromatin Regulatory Landscape during Mouse Preimplantation Development. Cell, 2016. 165(6): p. 1375-1388.

34. Swygert, S.G. and C.L. Peterson, Chromatin dynamics: interplay between remodeling enzymes and histone modifications. Biochim Biophys Acta, 2014. 1839(8): p. 728-36.

35. Ho, L. and G.R. Crabtree, Chromatin remodelling during development. Nature, 2010. 463(7280): p. 474-84.

36. Ho, L., et al., An embryonic stem cell chromatin remodeling complex, esBAF, is essential for embryonic stem cell self-renewal and pluripotency. Proceedings of the National Academy of Sciences, 2009. 106(13): p. 5181-5186.

37. Lessard, J., et al., An Essential Switch in Subunit Composition of a Chromatin Remodeling Complex during Neural Development. Neuron, 2007. 55(2): p. 201-215.

38. Corona, D.F.V., et al., ISWI Regulates Higher-Order Chromatin Structure and Histone H1 Assembly In Vivo. PLOS Biology, 2007. 5(9): p. e232.

39. Dirscherl, S.S. and J.E. Krebs, Functional diversity of ISWI complexes. Biochemistry and Cell Biology, 2004. 82(4): p. 482-489.

40. Konev, A.Y., et al., CHD1 Motor Protein Is Required for Deposition of Histone Variant H3.3 into Chromatin in Vivo. Science, 2007. 317(5841): p. 1087-1090.

41. Srinivasan, S., K.M. Dorighi, and J.W. Tamkun, Drosophila Kismet Regulates Histone H3 Lysine 27 Methylation and Early Elongation by RNA Polymerase II. PLOS Genetics, 2008. 4(10): p. e1000217.

42. Morrison, A.J. and X. Shen, Chromatin remodelling beyond transcription: the INO80 and SWR1 complexes. Nat Rev Mol Cell Biol, 2009. 10(6): p. 373-84.

43. Lyko, F., B.H. Ramsahoye, and R. Jaenisch, DNA methylation in Drosophila melanogaster. Nature, 2000. 408: p. 538.

44. Liyanage, V.R., et al., DNA modifications: function and applications in normal and disease States. Biology (Basel), 2014. 3(4): p. 670-723.

45. Venkatesh, S. and J.L. Workman, Histone exchange, chromatin structure and the regulation of transcription. Nature Reviews Molecular Cell Biology, 2015. 16: p. 178.

46. Henikoff, S. and A. Shilatifard, Histone modification: cause or cog? Trends in Genetics, 2011. 27(10): p. 389-396. 
47. Weber, C.M. and S. Henikoff, Histone variants: dynamic punctuation in transcription. Genes \& Development, 2014. 28(7): p. 672-682.

48. Lawrence, M., S. Daujat, and R. Schneider, Lateral Thinking: How Histone Modifications Regulate Gene Expression. Trends in Genetics, 2016. 32(1): p. 42-56.

49. Kouzarides, T., Chromatin modifications and their function. Cell, 2007. 128(4): p. 693-705.

50. Lewis, E.B., A gene complex controlling segmentation in Drosophila. Nature, 1978. 276(5688): p. 565-70.

51. Dura, J.M. and P. Ingham, Tissue- and stage-specific control of homeotic and segmentation gene expression in Drosophila embryos by the polyhomeotic gene. Development, 1988. 103(4): p. 733-741.

52. Schuettengruber, B., et al., Genome Regulation by Polycomb and Trithorax: 70 Years and Counting. Cell, 2017. 171(1): p. 34-57.

53. Schwartz, Y.B. and V. Pirrotta, A new world of Polycombs: unexpected partnerships and emerging functions. Nat Rev Genet, 2013. 14(12): p. 853-64.

54. Entrevan, M., B. Schuettengruber, and G. Cavalli, Regulation of Genome Architecture and Function by Polycomb Proteins. Trends Cell Biol, 2016. 26(7): p. 511-525.

55. Shao, Z., et al., Stabilization of Chromatin Structure by PRC1, a Polycomb Complex. Cell, 1999. 98(1): p. 37-46.

56. Grimaud, C., N. Negre, and G. Cavalli, From genetics to epigenetics: the tale of Polycomb group and trithorax group genes. Chromosome Res, 2006. 14(4): p. 363-75.

57. Kassis, J.A., J.A. Kennison, and J.W. Tamkun, Polycomb and Trithorax Group Genes in Drosophila. Genetics, 2017. 206(4): p. 1699-1725.

58. Klymenko, T., et al., A Polycomb group protein complex with sequence-specific DNA-binding and selective methyl-lysine-binding activities. Genes \& Development, 2006. 20(9): p. 11101122.

59. Kang, $\mathrm{H}$., et al., Sex comb on midleg $(\mathrm{Scm})$ is a functional link between PcG-repressive complexes in Drosophila. Genes \& Development, 2015. 29(11): p. 1136-1150.

60. Kassis, J.A. and J.L. Brown, Chapter Three - Polycomb Group Response Elements in Drosophila and Vertebrates, in Advances in Genetics, T. Friedmann, J.C. Dunlap, and S.F. Goodwin, Editors. 2013, Academic Press. p. 83-118.

61. Rose, N.R., et al., RYBP stimulates PRC1 to shape chromatin-based communication between Polycomb repressive complexes. eLife, 2016. 5: p. e18591.

62. Farcas, A.M., et al., KDM2B links the Polycomb Repressive Complex 1 (PRC1) to recognition of CpG islands. eLife, 2012. 1: p. e00205.

63. He, J., et al., Kdm $2 b$ maintains murine embryonic stem cell status by recruiting PRC1 complex to CpG islands of developmental genes. Nature Cell Biology, 2013. 15: p. 373.

64. Li, G., et al., Jarid2 and PRC2, partners in regulating gene expression. Genes \& Development, 2010. 24(4): p. 368-380.

65. Blackledge, Neil P., et al., Variant PRC1 Complex-Dependent H2A Ubiquitylation Drives PRC2 Recruitment and Polycomb Domain Formation. Cell, 2014. 157(6): p. 1445-1459.

66. Kalb, R., et al., Histone H2A monoubiquitination promotes histone H3 methylation in Polycomb repression. Nat Struct Mol Biol, 2014. 21(6): p. 569-71.

67. Klose, R.J., et al., Chromatin Sampling-An Emerging Perspective on Targeting Polycomb Repressor Proteins. PLOS Genetics, 2013. 9(8): p. e1003717.

68. Dietrich, N., et al., REST-mediated recruitment of polycomb repressor complexes in mammalian cells. PLoS genetics, 2012. 8(3): p. e1002494.

69. Yu, M., et al., Direct Recruitment of Polycomb Repressive Complex 1 to Chromatin by Core Binding Transcription Factors. Molecular Cell, 2012. 45(3): p. 330-343.

70. Attwooll, C., et al., A Novel Repressive E2F6 Complex Containing the Polycomb Group Protein, EPC1, That Interacts with EZH2 in a Proliferation-specific Manner. Journal of Biological Chemistry, 2005. 280(2): p. 1199-1208. 
71. Herranz, N., et al., Polycomb Complex 2 Is Required for E-cadherin Repression by the Snail1 Transcription Factor. Molecular and Cellular Biology, 2008. 28(15): p. 4772-4781.

72. Blackledge, N.P., N.R. Rose, and R.J. Klose, Targeting Polycomb systems to regulate gene expression: modifications to a complex story. Nature Reviews Molecular Cell Biology, 2015. 16: p. 643.

73. Basu, A., et al., YY1 DNA binding and interaction with YAF2 is essential for Polycomb recruitment. Nucleic Acids Research, 2014. 42(4): p. 2208-2223.

74. Bauer, M., J. Trupke, and L. Ringrose, The quest for mammalian Polycomb response elements: are we there yet? Chromosoma, 2016. 125(3): p. 471-496.

75. Brockdorff, N., Noncoding RNA and Polycomb recruitment. RNA, 2013. 19(4): p. 429-442.

76. Veraksa, A., M. Del Campo, and W. McGinnis, Developmental patterning genes and their conserved functions: from model organisms to humans. Mol Genet Metab, 2000. 69(2): p. 85-100.

77. Brooke, N.M., J. Garcia-Fernàndez, and P.W.H. Holland, The ParaHox gene cluster is an evolutionary sister of the Hox gene cluster. Nature, 1998. 392: p. 920.

78. Montavon, T. and N. Soshnikova, Hox gene regulation and timing in embryogenesis. Seminars in Cell \& Developmental Biology, 2014. 34: p. 76-84.

79. Izpisúa-Belmonte, J.C., et al., Murine genes related to the Drosophila AbdB homeotic genes are sequentially expressed during development of the posterior part of the body. The EMBO journal, 1991. 10(8): p. 2279-2289.

80. Gaunt, S.J., The significance of Hox gene collinearity. Int J Dev Biol, 2015. 59(4-6): p. 159-70.

81. Xue, S., et al., RNA regulons in Hox $5^{\prime}$ UTRs confer ribosome specificity to gene regulation. Nature, 2014. 517: p. 33.

82. Kondrashov, N., et al., Ribosome-Mediated Specificity in Hox mRNA Translation and Vertebrate Tissue Patterning. Cell, 2011. 145(3): p. 383-397.

83. Philippidou, P. and Jeremy S. Dasen, Hox Genes: Choreographers in Neural Development, Architects of Circuit Organization. Neuron, 2013. 80(1): p. 12-34.

84. Holland, P.W., Evolution of homeobox genes. Wiley Interdiscip Rev Dev Biol, 2013. 2(1): p. 31-45.

85. Struhl, G., Role of the $<e m>e s c</ e m><s u p>+</$ sup $>$ gene product in ensuring the selective expression of segment-specific homeotic genes in $\langle e m>$ Drosophila $</ e m>$. Journal of Embryology and Experimental Morphology, 1983. 76(1): p. 297-331.

86. Struhl, G. and M. Akam, Altered distributions of Ultrabithorax transcripts in extra sex combs mutant embryos of Drosophila. The EMBO Journal, 1985. 4(12): p. 3259-3264.

87. Suzuki, M., et al., Involvement of the Polycomb-group gene $<e m>R i n g 1 B</ e m>$ in the specification of the anterior-posterior axis in mice. Development, 2002. 129(18): p. 41714183.

88. Wang, J., et al., The mouse PCG gene eed is required for Hox gene repression and extraembryonic development. Mammalian Genome, 2002. 13(9): p. 493-503.

89. Li, X., et al., Mammalian Polycomb-Like Pcl2/Mtf2 Is a Novel Regulatory Component of PRC2 That Can Differentially Modulate Polycomb Activity both at the Hox Gene Cluster and at Cdkn2a Genes. Molecular and Cellular Biology, 2011. 31(2): p. 351-364.

90. Yaghmaeian Salmani, B., et al., Evolutionarily conserved anterior expansion of the central nervous system promoted by a common PcG-Hox program. Development, 2018. 145(7).

91. Soshnikova, N., et al., Duplications of hox gene clusters and the emergence of vertebrates. Dev Biol, 2013. 378(2): p. 194-9.

92. Soshnikova, N. and D. Duboule, Epigenetic Temporal Control of Mouse <em>Hox</em> Genes in Vivo. Science, 2009. 324(5932): p. 1320-1323.

93. Kmita, M. and D. Duboule, Organizing Axes in Time and Space; 25 Years of Colinear Tinkering. Science, 2003. 301(5631): p. 331-333. 
94. Duboule, D., The rise and fall of Hox gene clusters. Development, 2007. 134(14): p. 25492560.

95. Parker, H.J. and R. Krumlauf, Segmental arithmetic: summing up the Hox gene regulatory network for hindbrain development in chordates. Wiley Interdisciplinary Reviews:

Developmental Biology, 2017. 6(6): p. e286.

96. Marshall, H., et al., Retinoids and Hox genes. The FASEB Journal, 1996. 10(9): p. 969-978.

97. Knoblich, J.A., Mechanisms of asymmetric stem cell division. Cell, 2008. 132(4): p. 583-97.

98. Zhong, W. and W. Chia, Neurogenesis and asymmetric cell division. Curr Opin Neurobiol, 2008. 18(1): p. 4-11.

99. Chia, W., W.G. Somers, and H. Wang, Drosophila neuroblast asymmetric divisions: cell cycle regulators, asymmetric protein localization, and tumorigenesis. J Cell Biol, 2008. 180(2): p. 267-72.

100. Graybill, C., et al., Partitioning-defective Protein 6 (Par-6) Activates Atypical Protein Kinase C $(a P K C)$ by Pseudosubstrate Displacement. Journal of Biological Chemistry, 2012. 287(25): p. 21003-21011.

101. Caussinus, E. and C. Gonzalez, Induction of tumor growth by altered stem-cell asymmetric division in Drosophila melanogaster. Nature Genetics, 2005. 37: p. 1125.

102. Lee, C.Y., et al., Drosophila Aurora-A kinase inhibits neuroblast self-renewal by regulating aPKC/Numb cortical polarity and spindle orientation. Genes Dev, 2006. 20(24): p. 3464-74.

103. Wang, H., et al., Aurora-A acts as a tumor suppressor and regulates self-renewal of Drosophila neuroblasts. Genes \& Development, 2006. 20(24): p. 3453-3463.

104. Wang, H., et al., Polo inhibits progenitor self-renewal and regulates Numb asymmetry by phosphorylating Pon. Nature, 2007. 449: p. 96.

105. Paridaen, J.T. and W.B. Huttner, Neurogenesis during development of the vertebrate central nervous system. EMBO reports, 2014. 15(4): p. 351-364.

106. Konno, D., et al., Neuroepithelial progenitors undergo LGN-dependent planar divisions to maintain self-renewability during mammalian neurogenesis. Nature Cell Biology, 2007. 10: p. 93.

107. Wang, X., et al., Asymmetric centrosome inheritance maintains neural progenitors in the neocortex. Nature, 2009. 461: p. 947.

108. Paridaen, Judith T.M.L., M. Wilsch-Bräuninger, and Wieland B. Huttner, Asymmetric Inheritance of Centrosome-Associated Primary Cilium Membrane Directs Ciliogenesis after Cell Division. Cell, 2013. 155(2): p. 333-344.

109. Wilsch-Bräuninger, M., et al., Basolateral rather than apical primary cilia on neuroepithelial cells committed to delamination. Development, 2012. 139(1): p. 95-105.

110. Lehtinen, Maria K., et al., The Cerebrospinal Fluid Provides a Proliferative Niche for Neural Progenitor Cells. Neuron, 2011. 69(5): p. 893-905.

111. Mieko Mizutani, C. and E. Bier, EvoD/Vo: the origins of BMP signalling in the neuroectoderm. Nature Reviews Genetics, 2008. 9: p. 663.

112. Walsh, K.T. and C.Q. Doe, Drosophila embryonic type Il neuroblasts: origin, temporal patterning, and contribution to the adult central complex. Development, 2017. 144(24): p. $4552-4562$.

113. Álvarez, J.-A. and F.J. Díaz-Benjumea, Origin and specification of type II neuroblasts in the $<$ em>Drosophila</em> embryo. Development, 2018. 145(7).

114. Hartenstein, V. and A. Wodarz, Initial neurogenesis in Drosophila. Wiley Interdiscip Rev Dev Biol, 2013. 2(5): p. 701-21.

115. Akam, M., The molecular basis for metameric pattern in the Drosophila embryo. Development, 1987. 101(1): p. 1-22.

116. Lawrence, P.A. and G. Struhl, Morphogens, Compartments, and Pattern: Lessons from Drosophila? Cell, 1996. 85(7): p. 951-961.

117. Sprecher, S., DrosophilaNeural Development. 2012. 
118. Karcavich, R. and C.Q. Doe, Drosophila neuroblast 7-3 cell lineage: A model system for studying programmed cell death, Notch/Numb signaling, and sequential specification of ganglion mother cell identity. Journal of Comparative Neurology, 2005. 481(3): p. 240-251.

119. Bello, B.C., et al., Amplification of neural stem cell proliferation by intermediate progenitor cells in Drosophila brain development. Neural Dev, 2008. 3: p. 5.

120. Boone, J.Q. and C.Q. Doe, Identification of Drosophila type II neuroblast lineages containing transit amplifying ganglion mother cells. Dev Neurobiol, 2008. 68(9): p. 1185-95.

121. Bowman, S.K., et al., The Tumor Suppressors Brat and Numb Regulate Transit-Amplifying Neuroblast Lineages in Drosophila. Developmental Cell, 2008. 14(4): p. 535-546.

122. Baumgardt, M., et al., Global programmed switch in neural daughter cell proliferation mode triggered by a temporal gene cascade. Dev Cell, 2014. 30(2): p. 192-208.

123. Karlsson, D., M. Baumgardt, and S. Thor, Segment-Specific Neuronal Subtype Specification by the Integration of Anteroposterior and Temporal Cues. PLOS Biology, 2010. 8(5): p. e1000368.

124. Pearson, B.J. and C.Q. Doe, SPECIFICATION OF TEMPORAL IDENTITY IN THE DEVELOPING NERVOUS SYSTEM. Annual Review of Cell and Developmental Biology, 2004. 20(1): p. 619647.

125. Li, X., Z. Chen, and C. Desplan, Chapter Three - Temporal Patterning of Neural Progenitors in Drosophila, in Current Topics in Developmental Biology, A.E. Rougvie and M.B. O'Connor, Editors. 2013, Academic Press. p. 69-96.

126. Brody, T. and W.F. Odenwald, Programmed Transformations in Neuroblast Gene Expression during Drosophila CNS Lineage Development. Developmental Biology, 2000. 226(1): p. 34-44.

127. Baumgardt, M., et al., Neuronal subtype specification within a lineage by opposing temporal feed-forward loops. Cell, 2009. 139(5): p. 969-82.

128. Stratmann, J., et al., Neuronal cell fate diversification controlled by sub-temporal action of Kruppel. eLife, 2016. 5: p. e19311.

129. Rogulja-Ortmann, A., et al., Programmed cell death in the embryonic central nervous system of Drosophila melanogaster. Development, 2007. 134(1): p. 105-16.

130. Monedero Cobeta, I., B.Y. Salmani, and S. Thor, Anterior-Posterior Gradient in Neural Stem and Daughter Cell Proliferation Governed by Spatial and Temporal Hox Control. Curr Biol, 2017. 27(8): p. 1161-1172.

131. Hartenstein, V. and J.A. Campos-Ortega, Early neurogenesis in wild-typeDrosophila melanogaster. Wilhelm Roux's archives of developmental biology, 1984. 193(5): p. 308-325.

132. De Graeve, F., et al., The ladybird homeobox genes are essential for the specification of a subpopulation of neural cells. Dev Biol, 2004. 270(1): p. 122-34.

133. Higashijima, S., et al., eagle, a member of the steroid receptor gene superfamily, is expressed in a subset of neuroblasts and regulates the fate of their putative progeny in the Drosophila CNS. Development, 1996. 122(2): p. 527-536.

134. Dittrich, R., et al., The differentiation of the serotonergic neurons in the Drosophila ventral nerve cord depends on the combined function of the zinc finger proteins Eagle and Huckebein. Development, 1997. 124(13): p. 2515-2525.

135. Stemple, D.L., Structure and function of the notochord: an essential organ for chordate development. Development, 2005. 132(11): p. 2503-2512.

136. Martynoga, B., D. Drechsel, and F. Guillemot, Molecular Control of Neurogenesis: A View from the Mammalian Cerebral Cortex. Cold Spring Harbor Perspectives in Biology, 2012. $4(10)$.

137. Ochiai, W., et al., Periventricular notch activation and asymmetric Ngn2 and Tbr2 expression in pair-generated neocortical daughter cells. Molecular and Cellular Neuroscience, 2009. 40(2): p. 225-233.

138. Dong, Z., et al., Intralineage Directional Notch Signaling Regulates Self-Renewal and Differentiation of Asymmetrically Dividing Radial Glia. Neuron, 2012. 74(1): p. 65-78. 
139. McConnell, S., Strategies for the generation of neuronal diversity in the developing central nervous system. The Journal of Neuroscience, 1995. 15(11): p. 6987-6998.

140. Müller, T., et al., The Homeodomain Factor Lbx1 Distinguishes Two Major Programs of Neuronal Differentiation in the Dorsal Spinal Cord. Neuron, 2002. 34(4): p. 551-562.

141. Isshiki, T., et al., Drosophila neuroblasts sequentially express transcription factors which specify the temporal identity of their neuronal progeny. Cell, 2001. 106(4): p. 511-521.

142. Maurange, C., L. Cheng, and A.P. Gould, Temporal transcription factors and their targets schedule the end of neural proliferation in Drosophila. Cell, 2008. 133(5): p. 891-902.

143. Molyneaux, B.J., et al., Neuronal subtype specification in the cerebral cortex. Nature Reviews Neuroscience, 2007. 8: p. 427.

144. Budirahardja, Y. and P. Gönczy, Coupling the cell cycle to development. Development, 2009. 136(17): p. 2861-2872.

145. Lane, M.E., et al., A Screen for Modifiers of $<e m>$ Cyclin E</em $>$ Function in $<e m>$ Drosophila melanogaster $</$ em $>$ Identifies $<e m>C d k 2</ e m>$ Mutations, Revealing the Insignificance of Putative Phosphorylation Sites in Cdk2. Genetics, 2000. 155(1): p. 233-244.

146. Stern, B., et al., Genetic analysis of the Drosophila cdc2 homolog. Development, 1993. 117(1): p. 219-232.

147. Knoblich, J.A. and C.F. Lehner, Synergistic action of Drosophila cyclins A and B during the G2$M$ transition. The EMBO Journal, 1993. 12(1): p. 65-74.

148. Knoblich, J.A., et al., Cyclin E controls $S$ phase progression and its down-regulation during Drosophila embryogenesis is required for the arrest of cell proliferation. Cell, 1994. 77(1): $p$. 107-120.

149. Lindqvist, A., V. Rodríguez-Bravo, and R.H. Medema, The decision to enter mitosis: feedback and redundancy in the mitotic entry network. The Journal of Cell Biology, 2009. 185(2): p. 193-202.

150. Yang, A., et al., p73-deficient mice have neurological, pheromonal and inflammatory defects but lack spontaneous tumours. Nature, 2000. 404: p. 99.

151. Ohnuma, S., A. Philpott, and W.A. Harris, Cell cycle and cell fate in the nervous system. Current opinion in neurobiology, 2001. 11(1): p. 66-73.

152. Ohnuma, S., et al., p27Xic1, a Cdk inhibitor, promotes the determination of glial cells in Xenopus retina. Cell, 1999. 99(5): p. 499-510.

153. Yamaguchi, Y. and M. Miura, Programmed Cell Death in Neurodevelopment. Developmental Cell, 2015. 32(4): p. 478-490.

154. Kornbluth, S. and K. White, Apoptosis in $\langle e m>$ Drosophila</em>: neither fish nor fowl (nor man, nor worm). Journal of Cell Science, 2005. 118(9): p. 1779-1787.

155. Ryoo, H.D. and E.H. Baehrecke, Distinct death mechanisms in Drosophila development. Curr Opin Cell Biol, 2010. 22(6): p. 889-95.

156. Holland, N.D., Early central nervous system evolution: an era of skin brains? Nat Rev Neurosci, 2003. 4(8): p. 617-27.

157. Nielsen, C., Larval nervous systems: true larval and precocious adult. The Journal of Experimental Biology, 2015. 218(4): p. 629-636.

158. Holland, L.Z., et al., Evolution of bilaterian central nervous systems: a single origin? Evodevo, 2013. 4(1): p. 27.

159. Tosches, M.A. and D. Arendt, The bilaterian forebrain: an evolutionary chimaera. Curr Opin Neurobiol, 2013. 23(6): p. 1080-9.

160. Jékely, G., J. Paps, and C. Nielsen The phylogenetic position of ctenophores and the origin(s) of nervous systems. EvoDevo, 2015. 6, 1 DOI: 10.1186/2041-9139-6-1.

161. Arendt, D., M.A. Tosches, and H. Marlow, From nerve net to nerve ring, nerve cord and brain-evolution of the nervous system. Nat Rev Neurosci, 2016. 17(1): p. 61-72.

162. Martín-Durán, J.M., et al., Convergent evolution of bilaterian nerve cords. Nature, 2017. 553 : p. 45 . 
163. Kriegstein, A., S. Noctor, and V. Martínez-Cerdeño, Patterns of neural stem and progenitor cell division may underlie evolutionary cortical expansion. Nature Reviews Neuroscience, 2006. 7: p. 883.

164. Nielsen, C., How to make a protostome. Invertebrate Systematics, 2012. 26(1): p. 25-40.

165. Nielsen, C., Life cycle evolution: was the eumetazoan ancestor a holopelagic, planktotrophic gastraea? BMC Evol Biol, 2013. 13: p. 171.

166. Duffy, J.B., GAL4 system in Drosophila: a fly geneticist's Swiss army knife. Genesis, 2002. 34(1-2): p. 1-15.

167. Song, A.J. and R.D. Palmiter, Detecting and Avoiding Problems When Using the Cre-lox System. Trends in Genetics, 2018. 34(5): p. 333-340.

168. Xie, H., et al., Polycomb repressive complex 2 regulates normal hematopoietic stem cell function in a developmental-stage-specific manner. Cell Stem Cell, 2014. 14(1): p. 68-80.

169. Doe, C.Q., Neural stem cells: balancing self-renewal with differentiation. Development, 2008. 135(9): p. 1575-1587.

170. Homem, C.C.F. and J.A. Knoblich, $<$ em $>$ Drosophila</em> neuroblasts: a model for stem cell biology. Development, 2012. 139(23): p. 4297-4310.

171. Skeath, J.B. and S. Thor, Genetic control of Drosophila nerve cord development. Current Opinion in Neurobiology, 2003. 13(1): p. 8-15.

172. Technau, G.M., C. Berger, and R. Urbach, Generation of cell diversity and segmental pattern in the embryonic central nervous system of Drosophila. Dev Dyn, 2006. 235(4): p. 861-9.

173. de Nooij, J.C., M.A. Letendre, and I.K. Hariharan, A Cyclin-Dependent Kinase Inhibitor, Dacapo, Is Necessary for Timely Exit from the Cell Cycle during Drosophila Embryogenesis. Cell, 1996. 87(7): p. 1237-1247.

174. Lane, M.E., et al., Dacapo, a Cyclin-Dependent Kinase Inhibitor, Stops Cell Proliferation during Drosophila Development. Cell, 1996. 87(7): p. 1225-1235.

175. Rickert, C., et al., Progressive derivation of serially homologous neuroblast lineages in the gnathal CNS of Drosophila. PLoS One, 2018. 13(2): p. e0191453.

176. Urbach, R., D. Jussen, and G.M. Technau, Gene expression profiles uncover individual identities of gnathal neuroblasts and serial homologies in the embryonic CNS of Drosophila. Development (Cambridge, England), 2016. 143(8): p. 1290-1301.

177. Jamieson, K., et al., Regional control of histone H3 lysine 27 methylation in $<e m>$ Neurospora</em>. Proceedings of the National Academy of Sciences, 2013. 110(15): $p$. 6027-6032.

178. Dumesic, Phillip A., et al., Product Binding Enforces the Genomic Specificity of a Yeast Polycomb Repressive Complex. Cell, 2015. 160(1): p. 204-218.

179. Garcia-Fernandez, J., The genesis and evolution of homeobox gene clusters. Nat Rev Genet, 2005. 6(12): p. 881-92.

180. Choksi, S.P., et al., Prospero acts as a binary switch between self-renewal and differentiation in Drosophila neural stem cells. Dev Cell, 2006. 11(6): p. 775-89.

181. Fish, J.L., et al., Making bigger brains-the evolution of neural-progenitor-cell division. Journal of Cell Science, 2008. 121(17): p. 2783-2793.

182. Lui, Jan H., David V. Hansen, and Arnold R. Kriegstein, Development and Evolution of the Human Neocortex. Cell, 2011. 146(1): p. 18-36. 


\section{Papers}

The papers associated with this thesis have been removed for copyright reasons. For more details about these see:

http://urn.kb.se/resolve?urn=urn:nbn:se:liu:diva-147736 